ANUARIO DE Estudios Medievales

43/1, enero-junio de 2013, pp. 115-158

ISSN 0066-5061

doi:10.3989/aem.2013.43.1.05

\title{
ALIMENTACIÓN Y SALUD EN LA VALENCIA MEDIEVAL. TEORÍAS Y PRÁCTICAS ${ }^{1}$
}

\author{
FOOD AND HEALTH IN MEDIEVAL VALENCIA. \\ THEORIES AND PRACTICES
}

\author{
JUAN VICENTE GARCÍA MARSILLA \\ Universitat de València
}

\begin{abstract}
Resumen: Se pretende aquí un acercamiento a la relación entre los hábitos alimentarios y la salud en una ciudad mediterránea de la baja Edad Media a partir de la confrontación entre los tratados médicos, los recetarios gastronómicos y las fuentes de archivo que atestiguan los gastos reales en alimentos. A través de esa comparación, y utilizando registros contables de casas nobiliarias, empresas mercantiles, conventos y hospitales, se observan las pautas alimenticias que se aplicaban, y su mayor o menor concordancia con los principios galénicos de la medicina universitaria. Además, se intenta valorar cuáles eran los factores clave en la evolución de esas pautas, y hasta qué punto las teorías no venían más bien a sancionar los comportamientos de las elites sociales de la época.
\end{abstract}

Palabras clave: alimentación; salud; medicina; gastronomía; consumo; Valencia; Corona de Aragón; recetarios; regimina; siglos XIII-XV.

\begin{abstract}
The aim of this article is to provide an initial survey about the relationship between food habits and health in a Mediterranean city during the Late Middle Ages, by comparing medical treatises, gastronomic recipes and the archival sources that tell us about the actual expenses in food. Through this comparison, and by using accounting records of aristocratic houses, merchant enterprises, convents and hospitals, we can observe the dietary guidelines that were applied, and their concordance with the galenic principles of University medicine. Moreover, we attempt to assess what were the key factors in the evolution of these theories' guidelines, and how they were probably rather a way to approve the social behaviour of the social elites of these times.
\end{abstract}

Key words: food; health; medicine; gastronomy; consumption; Valencia; Crown of Aragon; recipes; regimina; 13th-15th centuries.

${ }^{1}$ Este estudio se enmarca en el Proyecto de Investigación "Una capital medieval y su área de influencia. El impacto económico y político de la ciudad de Valencia sobre el conjunto del reino en la baja Edad Media", HAR2011-28718 del Ministerio de Ciencia e Innovación. Abreviaturas empleadas: ACA = Arxiu de la Corona d'Aragó; ACV = Arxiu de la Catedral de València; $\mathrm{ADV}=$ Arxiu de la Diputació de València; AMV = Arxiu Municipal de València; APPV = Arxiu de Protocols del Patriarca de València (Arxiu del Col-legi del Corpus Christi); $\mathrm{ARV}=$ Arxiu del Regne de València; MR = Mestre Racional. 


\section{SUMARIO}

1. Humores y sabores.- 2. Lo caro es sano.- 3. Caer en la tentación.- 4. Bibliografía citada.

Cesó la música, sentóse Sancho a la cabecera de la mesa, porque no había más de aquel asiento, y no otro servicio en toda ella. Púsose a su lado en pie un personaje, que después mostró ser médico, con una varilla de ballena en la mano. Levantaron una riquísima y blanca toalla con que estaban cubiertas las frutas y mucha diversidad de platos de diversos manjares; uno que parecía estudiante echó la bendición, y un paje puso un babador randado a Sancho; otro que hacía el oficio de maestresala llegó un plato de fruta delante; pero apenas hubo comido un bocado, cuando el de la varilla tocando con ella en el plato, se le quitaron de delante con grandísima celeridad ${ }^{2}$.

El conocidísimo episodio de la segunda parte del Quijote que así comienza, y en el que, como parte de la burla ideada para Sancho Panza en la llamada "Ínsula Barataria", un médico situado a su lado irá desestimando como insanos todos los manjares que le ponían por delante, puede servir como perfecta ilustración del tema que pretendo abordar en las líneas que siguen, que no es otro que la relación existente entre medicina, gastronomía y alimentación a finales de la Edad Media, a partir en este caso del ejemplo valenciano. Es cierto que la escena es una parodia, una de tantas bromas pesadas que padeció el flamante y aparentemente ingenuo gobernador, pero como la mayoría de los pasajes de la obra de Cervantes, aquella era también la crítica de una práctica concreta que se había puesto de moda en las cortes señoriales al menos desde el siglo XIV. El mismo rey aragonés Pedro el Ceremonioso, en sus detalladas Ordinacions de Cort, requería precisamente eso, que

Nós en la taula menjants los nostres metges aquí appareyladament manam denant estar, e que Nós diligentment encauten per guardar de menjars incompetents e nocius; e si en qualque manera alcuna cosa davant Nós veninosa posar, o en altre qualque manera present ésser, vegen aquella tantost gitar facen d'aquí e remoure ${ }^{3}$

${ }^{2}$ M. de Cervantes, El ingenioso hidalgo, vol. II, cap. XLVII "Donde se prosigue cómo se portaba Sancho Panza en su gobierno", pp. 640-641.

${ }^{3}$ Ordinacions de la Casa, p. 98. 
y no era ni mucho menos el único, porque otros grandes nobles de la época, como los duques de Borgoña y de Berry, harían otro tanto años más tarde ${ }^{4}$. Esa práctica refleja la creciente preocupación de las clases privilegiadas de aquella sociedad por la salubridad de los alimentos que consumían y la influencia que la medicina universitaria comenzó a ejercer, al menos en teoría, sobre sus hábitos cotidianos. Hoy, en el mundo de las dietas, los productos light y el "culto al cuerpo", no es nada difícil identificarse con Sancho, sólo que a la amenazante presencia física del médico a nuestras espaldas la han venido a sustituir otros vigilantes más sutiles, como el sentimiento de culpa, reforzado por unos estrictos cánones de belleza y salud propagados por la publicidad y los medios de comunicación de masas. No está de más, en todo caso, conocer que esa cierta obsesión por las propiedades de lo que ingerimos y sus efectos sobre nuestro cuerpo tiene una larga historia, de la que aquí analizaremos uno de sus episodios más sugestivos.

El tema, desde luego, no es nuevo, ya que existe toda una polémica en torno a la naturaleza de las relaciones entre el auge de la medicina galénica en las recién nacidas universidades y la redacción de los primeros recetarios gastronómicos medievales, así como sobre la influencia del galenismo en algunos importantes cambios que tuvieron lugar entonces en la dieta de los europeos. En síntesis, algunos estudiosos, como Jean-Louis Flandrin, Rashmi Patni, Terence Scully o Ria Jansen-Sieben ${ }^{5}$, consideran a la medicina y a sus regimina sanitatis como la base de los libros de cocina, cuyo contenido se habría inspirado en los principios dietéticos dictados por los médicos, quienes habrían influido también en el consumo masivo de ciertos alimentos básicos, como por ejemplo la carne de animales jóvenes ${ }^{6}$. Otros, en cambio, con Bruno Laurioux a la cabeza, consideran que hay demasiadas contradicciones entre la tradición dietética y la culinaria como para ver en la segunda una consecuencia inmediata de la primera, y de alguna manera dejan traslucir la posibilidad de que, al menos en parte, las recomendaciones sobre la bondad de los alimentos podrían ser más bien la adaptación de la teoría médica a los gustos de las elites bajomedievales y no al contrario ${ }^{7}$. Sin pretender abundar más en esta discusión, aquí lo que intentaré es comparar y relacionar esos dos campos de

\footnotetext{
${ }^{4}$ La crónica de Olivier de la Marche, escrita en 1473, señala también que, cuando el duque se sentaba a la mesa, el médico se situaba detrás para aconsejarle, lo mismo que se observa en la escena del banquete de Año Nuevo de Las muy ricas horas del duque de Berry, de principios del siglo xv (C.M. Woolgar, Banquetes y ayunos, p. 168).

5 J.L. Flandrin, Diététique et gastronomie; R. Patni, L'assaisonnement dans la cuisine française; T. Scully, Du fait de cuisine; idem, Mixing it up in Medieval Kitchen; idem, The Art of Cookery; R. Jansen-Sieben, From Food Therapy.

${ }^{6}$ Sobre esto véase R.A. Banegas, Europa carnívora, especialmente pp. 48-63.

${ }^{7}$ B. Laurioux, L'histoire de la cuisine; idem, Cuisine et médecine au Moyen Âge.
} 
la producción escrita, de los que hay importantes testimonios en la Corona de Aragón, con los documentos de la práctica recogidos especialmente en los archivos valencianos, desde los libros de cuentas de casas nobiliarias, empresas mercantiles, conventos u hospitales, a las fuentes notariales o judiciales, que pueden ofrecernos una visión más cercana a la realidad de la aplicación de estos preceptos en la vida cotidiana de nuestros antepasados.

\section{HUMORES Y SABORES}

Comencemos pues por recordar los principios básicos de la medicina clásica, enunciados por Hipócrates (siglos V-IV a. C.) y sobre todo por Galeno (siglo II d. C.), que fueron redescubiertos en el Occidente medieval a través de la filosofía natural de los autores musulmanes de los siglos XI y XII, orientales como Avicena o Ibn Buțān, o andalusíes como Averroes ${ }^{8}$. Para ellos, todo el universo material está compuesto por cuatro elementos primarios e inasequibles de cuyas múltiples combinaciones surgen todos los seres: el fuego, el aire, el agua y la tierra. Dichos elementos contienen a su vez cuatro "cualidades": lo cálido, lo frío, lo seco y lo húmedo, que afectan tanto a los minerales como a los vegetales y a los animales, y que en el caso de éstos, y especialmente del cuerpo humano, darían lugar a cuatro humores o fluidos físicos presentes en todas las personas, que eran la sangre, la flema, la bilis amarilla y la bilis negra. Todos los seres humanos contienen los cuatro humores, y el ideal es el equilibrio entre ellos, lo que es prácticamente imposible de lograr ya que cada individuo tiene su propia "complexión" tendente al predominio de uno de ellos, la cual condiciona igualmente su personalidad. Así existen personas "sanguíneas", "flemáticas", "coléricas" -si se impone en ellas la bilis amarilla- o "melancólicas" -si lo hace la negra.

El papel del médico, que analizaba estos fluidos a través de las secreciones de sus pacientes, como la orina, el vómito o la sangre, era pues buscar en la medida de lo posible ese equilibrio, y una de las formas más directas era a través de la comida y la bebida, ya que también los alimentos estaban compuestos de los mismos elementos, en proporciones diferentes, y su ingesta podía así compensar las carencias o los excesos del organismo. Los tratados de medicina galénica conceden pues una importancia fundamental a la alimentación en su búsqueda de la salud, aunque, según Marilyn Nicoud, los primeros regímenes de salud medievales que se redactaron siguiendo esta tradición, los

\footnotetext{
${ }^{8}$ Véase por ejemplo L. García Ballester, La búsqueda de la salud, y sobre Ibn Buṭlān y las posteriores versiones del Tacuinum sanitatis, J.M. López Piñero, La medicina como norma, y sobre las versiones ilustradas de su obra F. Jerez, Els còdexs pictòrics.
} 
de la corte del emperador Federico II, de entre 1220 y 1230, no insistían tanto en el tema, y serían las nuevas traducciones de Galeno realizadas a finales de esa centuria, como la del De facultatibus alimentorum, realizada por Guillaume de Moherbec, y la popularización del Tacuinum sanitatis en latín, las que comenzaron a poner de manifiesto la necesidad de una dietética al servicio de las clases dominantes de la sociedad'.

Como socarronamente apuntó en su día Carlo Cipolla, cuesta explicar cómo esta teoría médica totalmente errónea siguió siendo un paradigma incontestado hasta el siglo XVIII, lo que para él es uno de los problemas más fascinantes de la historia cultural de Europa ${ }^{10}$. Pero lo cierto es que la creencia en el sistema humoral presidió durante más de cuatrocientos años la concepción del cuerpo humano y, a partir de ese sistema, el proceso digestivo era visto como una gran cocción que se desarrollaba en la marmita natural de nuestro estómago, con el calor animal como combustible, y las distintas especias y condimentos como agentes que contribuían a equilibrar la posible frialdad de los alimentos y ayudaban a cocerlos y asimilarlos ${ }^{11}$. Para favorecer una digestión adecuada y mantener así el cuerpo sano los tratadistas médicos aconsejaban pues seguir unas pautas de nutrición que evitaran los "desequilibrios humorales" y para ello incidían tanto en la naturaleza misma de cada alimento -si era seco o húmedo, cálido o frío, y en qué grado-, como en los matices que les podían añadir las formas de preparación culinaria o los productos con los que se condimentaran. Por ejemplo, el buey o el cerdo salado, al ser carnes secas, debían ser hervidas para añadirles humedad, mientras que el carnero o el cerdo fresco, de naturaleza húmeda, era mejor consumirlos asados directamente al fuego. Además, el carácter frío de algunas de esas carnes aconsejaría cocinarlas con abundantes especias, que eran cálidas y secas, e incluso se recomendaba trocearlas lo más fino posible para que las propiedades de dichos productos exóticos penetraran bien en ellas ${ }^{12}$.

Algunas de estas recomendaciones parecen partir del más elemental sentido común, como el hervir las carnes secas y duras, las más añejas, pero como vemos ese proceso culinario se vestía con un ropaje de compleja teoría médica que tuvo su máxima expresión en los ya citados regímenes de salud, un género que comenzó a difundirse en el siglo XIII a imitación del De regimi-

\footnotetext{
${ }^{9} \mathrm{M}$. Nicoud, La dietética medieval.

${ }^{10}$ C. Cipolla, Miasmi e umori, p. 15. Véase también sobre este tema M. Sentieri, Un'indagine sulle ragioni.

${ }^{11}$ Véase J.L. Flandrin, Condimentación, cocina y dietética. Son interesantes también los esquemas sobre este proceso, y su sustitución por el paradigma actual a partir del siglo XVII, que ofrece R. Laudan, Origen de la dieta moderna.

${ }^{12} \mathrm{P}$. Freedman, Lo que vino de Oriente, especialmente pp. 67-77. También E. Birlouez, À la table des seigneurs, pp. 117-119.
} 
ne sanitatis de Galeno y que en principio consistía en una articulada serie de consejos para la vida saludable. Entre los más antiguos destacan el Liber de conservanda sanitate de Juan de Toledo y, sobre todo, el primero redactado en lengua vernácula, el Régime du corps de Aldobrandino de Siena, escrito en francés en $1256^{13}$. Ya de los primeros años del siglo XIV, la obra más importante de este género en la Corona de Aragón es el Regimen sanitatis ad regem Aragonum, de Arnau de Vilanova, destinado en principio al uso personal del monarca Jaime II en momentos en que su salud era especialmente delicada, pero que aún en vida del autor fue traducido al catalán por el cirujano real Bernat Sarriera, muestra del prestigio y difusión que alcanzó y del convencimiento de que aquellas máximas eran aplicables de forma mucho más general, al menos para los que se pudieran permitir cumplirlas ${ }^{14}$. De hecho las obras del médico valenciano, y las de otros insignes representantes de la medicina de raíz clásica, comenzaron a ser frecuentes en las pequeñas bibliotecas particulares de nobles, clérigos y ciudadanos del país, y no sólo en las de profesionales del ramo, como el famoso Jaume Roig, o el también médico Joan Andrés, poseedor de una cirugia de mestre Arnau de Vilanova y un antidotari de mestre Arnau, además de libros de Hipócrates o Avicena, sino que también un abogado de Xàtiva, Tomàs Gabarda, podía tener en su casa, en el momento de su muerte, en 1440, siete libros de medicina, uno de ellos de mestre Arnau de Vilanova ${ }^{15}$.

Las normas dictadas por estos auténticos manuales de vida sana no se quedaron por tanto confinadas en los palacios de sus primeros destinatarios, sino que circularon y fueron de sobra conocidas por un sector muy amplio de la sociedad culta de la época, e incluso también entre las clases medias y populares, a través de la mediación de otros oficios relacionados con la salud, como

${ }^{13}$ Le Régime du corps de maître Aldebrandin de Sienne. A este libro se le añadió una dedicatoria a Beatriz de Saboya, duquesa de Provenza y suegra de Luís IX el Santo de Francia, aunque no parece que fuera un texto destinado en principio personalmente a ella.

${ }^{14}$ Edición a cargo de L. García Ballester y M. McVaugh, en Regimen sanitatis ad regem aragonum. La introducción, especialmente útil, es de P. Gil-Sotres, con la ayuda de J.A. Paniagua y L. García Ballester. Véase también la edición de las dos primeras versiones catalanas del texto (la de Sarriera y una del siglo XV) en Arnau de Vilanova. Volum II. Hay que destacar igualmente los textos del francés Bernard de Gourdon (de 1308) y del italiano Maino de Manieri (ca. 1330), entre los que más se preocupan por la dietética. En la obra de este último hay una parte especialmente interesante para la historia de la alimentación conocida como Opusculum de saporibus, dedicada básicamente a las salsas; sobre él L. Thorndyke, A Medieval Sauce-Book y T. Scully, The Opusculum de Saporibus.

${ }^{15}$ J. Sanchis Sivera, Bibliología valenciana medieval, reeditado en J. Sanchis Sivera, Estudis d'Història Cultural, p. 95. También algunos mercaderes de Barcelona disponían de libros de medicina, como se puede ver en J. Aurell, A. Puigarnau, La cultura del mercader. Sobre la difusión social de los preceptos médicos L. Cifuentes, La ciència en català. 
los cirujanos y los barberos ${ }^{16}$. Sólo así, considerando los regimina como textos destinados a una aplicación práctica, se entiende el interés por poseerlos, las numerosas ediciones que se hicieron de muchos de ellos y los conocimientos muy concretos sobre su contenido que parecen mostrar por ejemplo predicadores y moralistas como Francesc Eiximenis o Vicent Ferrer. De hecho, la popularización de los saberes médicos debió ser tal que Eiximenis llegó a criticar la práctica frecuente en la época de que personas completamente legas en la materia se dieran unas a otras consejos sobre la dieta a seguir, de manera que Aytal temps tenim huy en lo món que tothom se fa metge d'altre ${ }^{17}$. Unas palabras que serían perfectamente aplicables a nuestros días.

A estos textos de tipo más general se les añadieron más tarde otros, motivados por la irrupción de la peste negra en Europa, que trataban precisamente de prevenir la epidemia. Algunos fueron directamente encargados por las autoridades municipales, como el Regiment de preservació de pestilència de Jaume d'Agramunt, que hizo este médico para el consell de Lleida en el mismo año $1348^{18}$. Más tarde sería otro fuerte brote pestífero, padecido por la ciudad de Valencia entre 1489 y 1490, el que llevó a otro galeno, el converso Lluís Alcanyís, a escribir su Regiment preservatiu e curatiu de la pestilència, que tendría bastante aceptación y sería pronto llevado a la imprenta ${ }^{19}$. Se trata en ambos casos, como en algunos otros que se escribieron en Francia o Italia, de opúsculos no demasiado largos que basaban sus consejos en la concepción de la epidemia como una corrupción de los humores del aire, la cual por tanto también podía penetrar en los animales y las plantas. Por eso lo más seguro era evitar los alimentos provenientes de las zonas infectadas, y especialmente las frutas, cuya piel fina deja pasar los aires viciados, como también los quesos y los peces provenientes de aguas estancadas. Al comprobarse bien pronto además que la enfermedad llegaba especialmente en verano, los regiments comenzaron a recomendar los alimentos de naturaleza fría, habitualmente proscritos, como la calabaza o el melón, y desaconsejaron en cambio las especias más cálidas y el pan demasiado cocido, o conservado del día anterior, que podía generar humors cremades. Sin embargo la carne debía seguir siendo la de los animales jóvenes, asegurándose sólo de que hubieran comido buenos y sanos pastos ${ }^{20}$.

\footnotetext{
${ }^{16}$ Como razonadamente expone C. Ferragud, Medicina i promoció social.

${ }^{17}$ F. Eiximenis, Com usar bé de beure e menjar, p. 119.

${ }_{18}^{18} \mathrm{~J}$. d'Agramunt, Regiment de preservació de la pestilència. Agramunt sin embargo fue una de las primeras víctimas de la enfermedad en la ciudad del Segre.

${ }^{19}$ L. Alcanyís, Regiment preservatiu e curatiu.

${ }^{20}$ J.V. García Marsilla, La jerarquía de la mesa, especialmente pp. 89-91. También J. Gunzberg, La alimentación en los tratados.
} 
La preocupación por la edad de los animales que se consumían era efectivamente una de las más recurrentes en todos los tratados médicos, tanto los generales como los preventivos de la peste. De hecho Vilanova ofrece una especie de tabla de las "edades ideales" en que cada animal se podía llevar a las mesas de sus potenciales lectores. Se afirmaba en ella por ejemplo que la gallina se debía comer cuando comienza a poner, el capón con entre seis y ocho meses, el pavo real con entre un año y dieciséis meses, el faisán y el carnero de entre un año y año y medio, el conejo de entre cuatro y seis meses y los pollos con dien piu piu. En general, son edades tempranas que confirman la tendencia a preferir las carnes tiernas que comienza a observarse al final de la Edad Media. Vilanova distingue además las especies más adecuadas para consumir en cada estación, en relación naturalmente con sus grados de frío o calor y de humedad o sequedad, por lo que si algunas especies eran saludables todo el año, el verano era en general el momento de las aves más jóvenes y el invierno en cambio el de las gallinas viejas, las carnes saladas, la vaca y el jabalín ${ }^{21}$.

Las cuentas de las casas nobiliarias parecen seguir bastante de cerca estas recomendaciones. En el invierno de 1403, por ejemplo, el comprador de la reina María de Luna adquiría casi todos los días entre siete y ocho pares de gallinas, mientras que en la corte del duque de Gandia Alfons el Vell por la misma época se sacrificaban en esa estación entre dos y cuatro pares de estas aves criadas en su propio corral. Hasta marzo en cambio no empezaban a aparecer las perdices en ambos palacios, sobre todo por el inicio de la temporada de caza, y en verano, tal y como recomienda Vilanova, primaban por el contrario las aves más jóvenes, como los pollos, los perdigons o los colomins ${ }^{22}$.

Por otra parte, la predilección de los tratados médicos por los carneros de poca edad, de entre un año y año y medio como se ha dicho, encaja perfectamente con los usos de los poderosos. Los que consumía la reina María pesaban entre 10 y 15 libras carniceras (10’6 y 15’9 g), que respondería más o menos a animales de esa edad, que hoy llamaríamos más corderos que propiamente moltons $^{23}$. En cambio las piezas que se sacrificaban a diario en las carnicerías de Valencia eran ligeramente más grandes, no encontrándose ninguna por debajo de las 12 libras en 1437-1438, año en el que disponemos de las cuentas de todas las piezas despachadas en la Carnisseria Major y la Carnisseria Nova o del Palau de la ciudad ${ }^{24}$. Igualmente los restos óseos encontrados

\footnotetext{
${ }^{21}$ Arnau de Vilanova. Volum II, pp. 165-166.

${ }^{22}$ J.V. García Marsilla, La jerarquía de la mesa, p. 198-199.

${ }^{23}$ Ibidem.

${ }^{24}$ Ese año la sisa de la carn, el impuesto indirecto sobre este producto, no se consiguió arrendar, por lo que fue gestionado directamente por el municipio, que llevó las cuentas de todo el 
en la Carnisseria de la Xerea, de principios del siglo XIV, demuestran que la mayoría de los animales que allí se sacrificaron eran carneros machos de entre dos y tres años, adultos jóvenes en los que se buscaba el equilibrio entre el tamaño del animal, y por tanto su rentabilidad en carne, y su grado de ternura, lo que llevaba a matar a los animales a una edad algo por encima de la recomendada por los médicos ${ }^{25}$. También en estas excavaciones los huesos de porcino que se hallaron eran de ejemplares muy jóvenes, todos menores de tres años, incluyendo un cochinillo de pocos meses. Y la predilección por los animales tiernos era aún más destacada en el caso del ganado caprino, porque mientras el cabró o macho cabrío era una especie poco consumida, salvo en las comunidades mudéjares, la de cabrito en cambio no sólo era carne cara, sino que se la consideraba especialmente apropiada para los enfermos ${ }^{26}$. Su consumo era frecuente por ejemplo en los hospitales, como el de Santa Llúcia o de la Reina de Valencia, donde en el año 1406 aparece con cierta frecuencia la compra de pequeñas cantidades de esta vianda, e incluso se llega a anotar como cabrit a malalts ${ }^{27}$. El cabrito es de hecho expresamente mencionado, junto con los corderos de un año y las terneras jóvenes, entre las carnes más propias para las personas que estaban en la "segunda edad", es decir, entre los 14 y los 35 años, en el De conservatione vitae humanae de Bernat de Gourdon, compañero de Arnau de Vilanova en la Universidad de Montpellier ${ }^{28}$.

En el extremo opuesto de las recomendaciones médicas estaba la casquería, por ello poco apreciada y por tanto barata, y sobre todo la carne de animales defectuosos o enfermos. Respecto a la primera, Arnau de Vilanova sólo acepta, que no recomienda, el hígado y los sesos de cabrito, mientras que afirma que cerveyls de totes altres coses animades qui agen IIII peus, e budels

ganado que llegaba a estas carnicerías y de su venta, con detalles sobre el peso. En total fueron 47.404 carneros y 117 machos cabríos entre junio de 1437 y abril de 1438 (AMV, Cuentas de la administración de las carnes, $\mathrm{g}^{2}-1$ ); véase J.V. García Marsilla, La Sisa de la Carn.

${ }_{25}^{25}$ J.V. García Marsilla, M.D. López Gila, M. Rosselló, Localització d'unes possibles carnisseries.

${ }^{26}$ El especial aprecio de los mudéjares valencianos por el ganado caprino en J.V. García Marsilla, Diferencia e integración, p. 355.

${ }^{27}$ AMV, Hospital de la Reina 346-1, vol. 1, f. 27r, 13 de agosto, "cabrit a malalts - X d." También en la corte navarra de Carlos III el Noble se compraron en 1411 cabritos y carneros "por los enfermos" (F. Serrano Larráyoz, La mesa del rey, p. 249). El cabrito es además la carne habitual del domingo de Pascua en los hospitales valencianos, como se ve en el ya citado de la Reina, en cuyas cuentas del año 1410 se consigna: "Ítem costà hun cabrit per a dar refrescament als pobres en les festes de Pasqua a XXIII de març - VII s. VI d." (AMV, Hospital de la Reina 346-1, vol. 2, f. 52r), sobre este hospital M. Gallent, La asistencia sanitaria en Valencia; o en el d'En Clapers de 1423, en cuya anotación del 6 de abril se lee "per compra de hun cabrit que havia comprat per a menjar lo jorn de Pasqua proper pasada e fon quatre del dit mes de abril - V s." (AMV, Hospital d'En Clapers 350-2, vol. 2, f. 42v).

${ }^{28}$ Bernard de Gordon, De conservatione vitae humanae, p. 55, citado por R.A. Banegas, Europa carnívora, p. 58. 
de totes coses animades, e ventres, e ronyons, e melses, deuen ésser esquivat $z^{29}$. Sin embargo, entre las tablas de la Carnisseria Major de Valencia había una llamada precisamente de les tripes, especializada pues en esos budells que tan nocivos les parecían a los médicos y en los embutidos que se preparaban con ellos $^{30}$. Y de hecho en la corte de Alfons el Vell de Gandia se compraba con cierta frecuencia casquería, especialmente hígados, pero también sesos, tripas, turmas y otras piezas en principio poco valoradas del carnero como la cabeza o los pies. Aunque es posible que en parte esa carne fuera destinada a los sirvientes de la casa, una proporción no despreciable iba a parar a la mesa del señor, al que por ejemplo le servían algunos días la cabeçola de un cabrito después de haberse comido un cuarto del mismo o le confeccionaban con hígado salsas o sofritos $^{31}$. Esas salsas aparecen incluso en los recetarios más famosos, como la salsa de pagó, que el Llibre de Sent Soví, de principios del siglo XIV, recomienda elaborar con vientres de gallinas y corazones de estos mismos animales y de conejos, junto con otros muchos ingredientes, lo que contradice abiertamente las prescripciones médicas ${ }^{32}$.

Desde luego, lo que no entraría nunca en la cesta de la compra de una corte nobiliaria como ésta sería carne como la rafalina o defectuosa que se vendía por ejemplo a mitad de precio en las carnicerías de Orihuela ${ }^{33}$, o como los "cerdos leprosos" (porcs mesells) de los que se surtía la tabla de carnes peligrosas de Porta Ferrissa, en Barcelona, aún sabiendo sus clientes que, según los médicos, podían contagiarse de dicha enfermedad por comerla ${ }^{34}$. Y por supuesto sería muy raro que, como hacían algunos para conseguir carne barata, aristócratas como éstos le compraran a sus vecinos judíos la llamada carne truffana, que los rabinos habían rechazado por algún defecto en la matanza kosher o igualmente por haber encontrado enfermedades o malformaciones en el animal una vez abierto y examinadas sus entrañas ${ }^{35}$.

Quienes no tenían más remedio que comprar estas carnes no se podían permitir tampoco gastar mucho en especias y condimentos para sazonar-

\footnotetext{
${ }^{29}$ Arnau de Vilanova. Volum II, p. 170.

${ }^{30}$ Tabla arrendada junto con otras por Joan Armenguer, "síndic e procurador dels senyors útils de les taules de la Carnisseria Major", en 1414 y 1415 (J.V. García Marsilla, La jerarquía de la mesa, p. 109).

${ }^{31}$ J.V. García Marsilla, La taula del senyor duc, pp. 45-46.

${ }^{32}$ Llibre de Sent Soví, p. 63.

${ }^{33} \mathrm{Al}$ menos pagaba la mitad de impuestos o sisas (J.A. Barrio, Finanzas municipales, p. 41).

${ }^{34}$ En realidad no se trataba de lepra, sino la llamada cisticercosis del cerdo, por la que los humanos podían contraer la tenia, pero desde luego no la lepra (R.A. Banegas, Europa carnívora, pp. 132-136).

${ }^{35}$ J.V. García Marsilla, Puresa i negoci. También J. Riera i Sans, La conflictivitat de l'alimentació.
} 
las, por lo que, como ya se ha advertido más de una vez, es completamente falsa la premisa de que el gusto por los platos muy especiados, propio de la cocina medieval, se debiera a cualquier intento de enmascarar la carne o el pescado en malas condiciones ${ }^{36}$. Cuando algunos médicos, como Lluís Alcanyís, denuncian las salses ab les quals les carns se preparen per corregir alguna malícia d'elles, no se están refiriendo a los efectos de la putrefacción o a alteraciones tóxicas, sino a las contraindicaciones que esos alimentos podían tener desde el punto de vista de los desequilibrios humorales del cuerpo ${ }^{37}$. De hecho, desde ese punto de vista, P. Freedman señala que uno de los grandes atractivos de estos productos exóticos fue desde bien pronto su naturaleza medicamentosa, el hecho de que, además de ofrecer un festín al paladar, éste fuera, según la mentalidad de la época, un placer saludable ${ }^{38}$. No sería ésta la única razón para el indudable éxito de las especias hasta el siglo XVII, pues habría que añadir las propias tendencias hedonistas de los consumidores, ávidos de nuevas sensaciones gustativas, el prestigio de unos productos de procedencia ignota, algunos de los cuales incluso se pensaban directamente llegados del Paraíso Terrenal, y sobre todo la distinción social que aportaban a sus consumidores habituales ${ }^{39}$; pero sin duda la opinión favorable de los médicos sería la que le conferiría a estos productos y al uso y abuso de los mismos en las artes culinarias, un mayor marchamo de respetabilidad.

Es cierto, sin embargo, que no todas las especias eran iguales, y que los seguidores del galenismo hicieron todo lo posible por distinguir las propiedades específicas de cada una de ellas y sus posibles combinaciones con otros alimentos. En general los médicos aconsejaban una cierta moderación con estos condimentos fuertes, porque para ellos sería como si las personas sanas abusaran de las medicinas, lo que podría tener consecuencias negativas, como un inmoderado incremento del apetito, o el enmascarar y hacer deseables alimentos que por su propia naturaleza no se deberían ingerir ${ }^{40}$. Pero esa moderación sería, desde un punto de vista actual, muy relativa, porque los médicos, buenos conocedores de la cocina de su época, ofrecían recetas de salsas realmente fuertes: la pólvora de que hom dèu fer salça recomendada por Arnau de Vilanova, por ejemplo, incluía jengibre blanco, cilantro, cardamomo, rasura de vori (raspadura de marfil), clavo, azafrán y canela, junto con

\footnotetext{
${ }^{36}$ J.L. Flandrin lo ha aclarado en varios trabajos suyos, como por ejemplo en Condimentación, cocina y dietética, especialmente pp. 624-627.

${ }^{37}$ L. Alcanyís, Regiment preservatiu, p. 144.

${ }^{38}$ P. Freedman, Lo que vino de Oriente, p. 78.

${ }^{39}$ Sobre esta razón véase P. Freedman, Lo que vino de Oriente, y J.L. Flandrin, Condimentación, cocina y dietética.

${ }^{40}$ P. Gil-Sotres, Regimen sanitatis ad regem aragonum: Introducción, p. 208.
} 
almendras y vinagre o agraz ${ }^{41}$. Vemos ya en todo caso como en esta especie de "salsa multiusos", buena para cualquier tipo de alimentos, que aparece en la versión de principios del siglo XIV del regiment de Vilanova, está ya ausente la pimienta, que había sido la especia por excelencia desde la época romana hasta el siglo XIII, cuando aún algunos canónigos de la catedral de Valencia exigían cobrar parte de sus rentas en libras de este producto ${ }^{42}$. Los médicos en cambio comenzaron a considerar a la pimienta demasiado cálida y seca, alcanzando el cuarto y máximo grado en ambas cualidades, equivalente al que tenían condimentos locales como el ajo o la mostaza. Por eso Arnau de Vilanova proscribía lo que él consideraba fortz salses, como la pebrada o la aylada, y los "sabores agudos" como el de la mostaza, a no ser que se atemperasen con agua, vinagre, almendras y un poco de canela ${ }^{43}$. Sin duda había comenzado una época de fuerte desprestigio de la pimienta, que haría que en el siglo XV se la llegara a considerar un condimento rústico, apropiado sólo para los estómagos fuertes de los aldeanos, tal y como lo atestiguan tanto los tratados médicos más tardíos como los mismos recetarios y hasta la literatura ${ }^{44}$.

El verdadero problema es determinar si ese descenso de la reputación de la pimienta se debió a la opinión de los médicos o más bien fue al contrario, y en realidad fue la mayor accesibilidad a este condimento, que sobre todo los venecianos hacían llegar ya por toneladas a Europa, el que hizo que la pimienta se apartara tanto de las cocinas de los poderosos como de los consejos de sus médicos. La respuesta no es fácil, pero en todo caso las fuentes que nos hablan del consumo real de estos productos y de sus precios nos informan por ejemplo de que en ámbitos tan supuestamente tutelados por los médicos como los hospitales, las compras de pimienta eran habituales. Así, en el Hospital de la Reina de Valencia, la salsa que se compraba para uso diario tenía a la pimienta como elemento más abundante, al que complementaban el jengibre, la canela, el azafrán y el clavo, en cantidades menores ${ }^{45}$. En realidad ese predo-

\footnotetext{
${ }^{41}$ Arnau de Vilanova. Volum II, p. 179-180.

${ }^{42}$ Como Bernat de Vilar, que el 9 de abril de 1256 establecía a Bernat de Camarasa una casa en la parroquia de Sant Bartomeu de Valencia, que antes de la conquista cristiana había sido una mezquita, por un censo de una libra de pimienta al año a pagar en Pascua (ACV, Pergaminos 4.636).

${ }^{43}$ Arnau de Vilanova. Volum II, p. 178.

${ }^{44} \mathrm{P}$. Freedman, Lo que vino de Oriente, p. 59. Entre sus fuentes hay incluso una obra apócrifa de Arnau de Vilanova, que se remonta en realidad al siglo XV, y que considera la pimienta como una especia de rústicos, apta para las habas y los guisantes. Véase también sobre este proceso, B. Laurioux, Spices in the Medieval diet, p. 54, y M. Giagnacovo, Mercanti a tavola, p. 267.

${ }^{45}$ Media libra de pimienta, junto con dos onzas de jengibre, una onza de canela, media de azafrán y un cuarto de clavo formaban la salsa que se compró el 12 de abril de 1410 a cambio de 6 sueldos y 4 dineros (AMV, Hospital de la Reina 346-1, vol. 2, 1410, f. 9v). Poco después se compró "salça obs del espitall", compuesta por media libra de pimienta, dos onzas de jengibre y media onza de azafrán por 4 sueldos y 10 dineros (f. 10r), y el 18 de diciembre de ese año la
} 
minio de la pimienta se debía a su precio más bajo, porque mientras una libra costaba entre 4 y 7 sueldos, la de jengibre valía entre 6 y 8 , la de canela 12, la de clavo 20 y la de azafrán $36^{46}$. En el Hospital d'en Clapers de la misma ciudad no entraba en el siglo XIV más condimento que la sal, siendo el azúcar o la salsa mòlta consideradas directamente en el apartado de las medicinas que se compraban al especier, mientras que, ya en el siglo XV, la genérica salsa aparecía entre los alimentos de los días de fiesta ${ }^{47}$. En la leprosería u Hospital de Sant Llàtzer en cambio se compraba específicamente pimienta, junto a hierbas locales como el perejil o los brotons, a precios realmente baratos-dos sueldos y medio la libra- e incluso podemos encontrar algún plato concreto para el que la usaban, como las espinacas y el atún que se sazonaban con ella en 1450. La canela en cambio, la otra especia que aparece en las cuentas del lazareto, sólo aparece junto con el azúcar para elaborar los granyons o especie de churros que se ofrecían a los visitantes ilustres el día del santo patrón ${ }^{48}$. Por tanto, a la hora de confeccionar las salsas de los hospitales valencianos no se tenía tanto en cuenta la condición de enfermos de muchos de los que allí residían como la de pobres de todos ellos, de manera que la especia menos apreciada por los médicos era en cambio la más utilizada, porque era la que estaba más al alcance de aquel sector desfavorecido de la sociedad.

Pero incluso en las cortes señoriales se observa una pervivencia de la denostada pimienta, adquirida, eso sí, a precios más asequibles que las demás especias. La misma corona invertía grandes cantidades en ella, aunque no fuera ya el condimento principal. En 1399, con motivo de la coronación de Martín el Humano en Zaragoza, el futuro rey le envió un memorial a su comprador en Barcelona, Guillem Sarrià, con todo lo que debía adquirir para el

\footnotetext{
"salça per a l'espitall" la formaban media libra de pimienta, cuatro onzas de jengibre, una de azafrán, una de canela y un cuarto de clavos (f. 10v).

${ }^{46} \mathrm{El}$ azafrán, pese a ser de producción local, ya era entonces más caro que el oro, debido al escaso peso de los estambres. Véase sobre su producción y comercio P. Verdés, Una espècia autòctona. El alto precio del clavo o clavell de girofle por su parte se debe también en parte a su uso en la confección de perfumes y productos de belleza, como denunciaba Jaume Roig de una de sus perversas esposas que "sols clau tenia/ al seu mig cofre/ ple de girofle/ e drogueries" (J. Roig, Llibre de les dones o Spill, p. 56).

${ }^{47}$ Sobre este hospital en el siglo XIV, A. Rubio Vela, Pobreza, enfermedad y asistencia hospitalaria; los datos del siglo XV provienen directamente del archivo. Una compra de salsa, junto a turrones y miel, se consigna el 17 de marzo de 1427 (AMV, Hospital d'en Clapers 350-2, cuaderno 3, f. 42v). La misma indefinición sobre la salsa, comprada ya hecha, la encontramos en otras instituciones caritativas como las almoines catedralicias catalanas, véase por ejemplo P. Bertran, El menjador de l'Almoina, pp. 104-105, y M. Echániz, La alimentación de los pobres, p. 183.

${ }^{48}$ AMV, Hospital de Sant Llàtzer 353-1, tercer cuaderno, f. 23v. Ese mismo día se compra, para los granyons, además de trigo, azúcar y amelló, dos onzas de canela a 6 dineros cada una, es decir, a 6 sueldos la libra. Sobre este hospital, C. García Verdeguer, Una meselleria en la Valencia del Quinientos.
} 
evento, incluyendo un quintar de pimienta, por 300 sueldos, quintar y medio de jengibre por 900, dos quintars de canela por 1.200, 30 libras de azafrán por 1.000 , dos arrobas de clavo por $800 \mathrm{y}$ una càrrega de azúcar por $1.720^{49}$. En la corte de los duques reales de Gandia, por su parte, se compraban con frecuencia conjuntamente las tres especias que se consideraban básicas en su despensa: la pimienta, el jengibre y la canela, aunque casi siempre estas dos últimas tenían un precio que solía duplicar el de la primera ${ }^{50}$. Incluso en fechas bien tempranas, como 1368, se puede ya observar la distinta valoración de cada especia cuando los enviados del duque acudían a Valencia para proveer su despensa. En junio de ese año compraron en la capital cuatro libras de azúcar en panes por 30 sueldos (a 7’ 5 sueldos la libra), una libra de jengibre por 12 sueldos, otra de canela por 6 sueldos y 2 dineros, 2 de pimienta por 9 sueldos (a 4'5 sueldos cada una) y una de azafrán por 18 sueldos y medio, con un gasto total de 75 sueldos y 8 dineros $^{51}$.

Los precios de cada especia iban pues fluctuando, quizá anualmente, en función de las cantidades que llegaran en las galeras venecianas y de las mismas tendencias del gusto, y, aunque la pimienta siempre era la más barata, no por ello dejaba de adquirirse en estos entornos aristocráticos. También en la corte de la esposa de Martín el Humano, María de Luna, las cantidades de pimienta que se compraron en los nueve meses de 1403 que tenemos documentados superaron con diferencia a las de otros sazonadores, alcanzando los 32'427 $\mathrm{kg}$, bastante lejos de la segunda más presente, el jengibre, del que se adquirieron 13 '813 kg ${ }^{52}$. En las mesas más modestas de los ciudadanos la aparición de especias importadas sería en cambio bastante más excepcional, como en la factoría Datini de Valencia, donde se cocinaba más bien con hierbas locales, como el perejil, el hinojo, el anís o la salvia, de manera que en la anualidad 1404-1405 sólo se compró jengibre en siete ocasiones, pimienta en cuatro y canela una sola $v^{2} z^{53}$, y ello a pesar de que los cargamentos de especias pasaban a menudo en grandes cantidades por su tienda, sobre todo los de jengibre y canela $a^{54}$.

${ }^{49}$ ACA, Reial Cancelleria 2.240, f. 182v, recogido por D. Girona Llagostera, Itinerari del rey en Martí, p. 139. El quintar equivale a $41^{\prime} 5 \mathrm{~kg}$ y la arroba a $10^{\prime} 4 \mathrm{~kg}$.

${ }^{50} \mathrm{Si}$ la pimienta rondaba entre los 3 sueldos y medio y 6 sueldos la libra en Gandia, el jengibre y la canela variaban entre los 7 y los 10 y medio, en cambio en Benavarre, posesión pirenaica del duque, los precios se equiparaban, quizá por las dificultades del transporte (J.V. García Marsilla, La taula del senyor duc, pp.118-120).

${ }^{51}$ ARV, MR 12.540, f. 11v.

${ }_{52}$ J.V. García Marsilla, La jerarquía de la mesa, pp. 205-206.

53 J.V. García Marsilla, L'alimentazione in ambito mercantile, pp. 836-837. Desgraciadamente en ningún caso se especifica la cantidad comprada.

${ }^{54} \mathrm{El} 4$ de junio de 1396, por ejemplo, una carta hacía referencia a la recepción de 68 libras de pimienta, 100 de jengibre y 100 de canela fina, junto a otras muchas mercancías, como telas, cera o colorantes (A. Orlandi, Mercaderies i diners, pp. 304-305). 
La progresiva depreciación de la pimienta no supuso pues, ni mucho menos, su desaparición de los mercados, pese a todas las prevenciones médicas, sino todo lo contrario, al ampliarse su consumo a capas más modestas de la sociedad. Ello tuvo como consecuencia su creciente rechazo por parte de los cocineros de las elites, que sin embargo es más visible en otros países, como Francia, que en la Corona de Aragón, porque en los recetarios catalanes, como el Llibre de Sent Soví, la pimienta aparece como condimento para los cabritos o los lechones asados y en diversas salsas, como el migraust o la camalina, aunque no en muchas otras, en las que predominan el jengibre, la canela, el azúcar y las nous de xarc o "granos del paraíso" "55. En el Llibre del coc, más de cien años posterior, la pimienta desaparecería por ejemplo del migraust y de otras salsas, mientras que se multiplicaba la presencia del azúcar o de la nuez moscada ${ }^{56}$.

Sí se puede ver una cierta influencia de la teoría médica en la forma de diluir o destemprar estas salsas, que consistía muchas veces en disolver el polvo machacado en el mortero en líquidos de sabor agrio, como el vinagre, el agraz o los zumos de limón o naranja, lo que contribuía a "enfriar" su naturaleza cálida y a rebajarles también sequedad, añadiendo además con frecuencia otras sustancias que podían restar fuerza al potente "curry" de especias que constituía la base, como leche de almendras o miga de pan. Si a todo ello le añadimos edulcorantes como la miel o el azúcar, más los caldos de carne y los sofritos de cebolla e hígado, el resultado eran salsas que proporcionaban un gran abanico de sabores, pero que seguramente serían un tanto agresivas para los estómagos delicados, lo que hacía que fuera habitual recurrir a ciertas grageas medicinales para acabar los banquetes, como aquella dragea per repeembre los fums e per confortar l'estómech e per gitar de mi matex ventositats qui.s solen levar dins l'om con la que acababa sus banquetes el clérigo bon vivant que nos cuenta su opulenta dieta habitual en uno de los exempla de Francesc Eiximenis ${ }^{57}$.

\section{LO CARO ES SANO}

Dicho clérigo, en el Terç del Crestià, le escribe a un médico para que juzgue sus hábitos cotidianos, que constituyen el paradigma de todos los lujos gastronómicos del momento, y un ejemplo interesado de la molicie en la que,

\footnotetext{
${ }^{55}$ Como en la salsa de pagó o en la gingebrada (Llibre de Sent Soví, pp. 65-70).

${ }^{56} \mathrm{M}$. Robert, Libre del coch.

${ }^{57}$ F. Eiximenis, Com usar bé de beure e menjar, pp. 43-44.
} 
según criticaban los franciscanos como el autor, vivían algunos canónigos de la época. No vamos a reproducir aquí íntegra la carta por su extensión y porque es de sobra conocida, pero lo que podemos destacar es que su redacción intenta acomodarse a las que eran las prescripciones básicas para la dieta de los poderosos: comer los mejores y más valorados productos, entre ellos pan blanco ( $p$ a floret en la carta) y carnes tiernas, variar de aves en función de la estación, tomar salsas espesas y hervidas, acabar cada comida con quesos y azúcar, comer pescado de tall y no especies pequeñas, beber los mejores vinos aromáticos, tomar neules (barquillos) con azúcar, beber refrescos y jarabes en verano y hasta bañarse con frecuencia, recibir lavativas o dormirse escuchando el trino de los pájaros. Nada, por tanto, debería escandalizar por ejemplo a un médico de la aristocracia, y sin embargo, la respuesta de este galeno es contundente: vostra folla letra he reebuda, qui resposta no mereix, car havets perdut lo seny e no sabets on vós sots ${ }^{58}$. Le siguen despiadadas críticas en las que asoma el espíritu de la pobreza mendicante, pero sobre todo el franciscano le afea que se haya dado a los lujos, no tanto por su condición de miembro tonsurado de la Iglesia, como por su origen campesino, y le espeta que debe volver a comer pa d'ordi, e a mengar cebes e aylls, e a vegades un poch de carnsalada, e que beguats de la aygua axí com lavors fèyets o del vinagre ben amerat.

Surge aquí con fuerza otro de los rasgos supuestamente básicos de la medicina medieval, muy imbricada con la ideología dominante, como es su carácter clasista, su convencimiento de que cada cuerpo necesita de alimentos y cuidados distintos en función del estamento al que perteneciera su dueño. Sin embargo, hay que decir que la mayor parte de las afirmaciones en este sentido no parten de obras médicas, sino de referencias en obras literarias, cultas o populares, o hasta de algunos recetarios de cocina, que diseñan dietas diferentes en función de la condición social de cada uno, como el de Jean de Bockenheim, cocinero del papa Martín $\mathrm{V}^{59}$. Se convirtió por ejemplo prácticamente en un topos literario la historia del campesino que asciende en la escala social y comienza a comer manjares que no eran propios de su estatus inicial, por lo que enferma gravemente, hasta que muere -en algunas versiones- o vuelve a su régimen inicial y sana -en otras. Esa historia la encontramos en Francia, donde un campesino casado con una burguesa que le obsequia con refinadas viandas debe volver a las judías verdes, los guisantes y las sopas de leche para recuperarse ${ }^{60}$. Aparece también, aunque ya en el siglo XVI, en Italia,

${ }^{58}$ Ibidem, p. 46.

${ }^{59} \mathrm{~B}$. Laurioux, Le registre de cuisine.

${ }^{60}$ M. Montanari, L'image du paysan, p. 103. 
en la historia de Bertoldo, del escritor boloñés Giulio Cesare Croce, donde un montañés acostumbrado a comer nabos es adoptado por un rey y cae enfermo. Los médicos le administran los mejores alimentos pero él no deja de pedir nabos cocidos en ceniza y habas. No le hacen caso y Bertoldo muere. Sobre su tumba se fija entonces un epitafio irónico: "El que está acostumbrado a comer nabos no debe comer pastel" ${ }^{61}$. Bastante anterior es el ejemplo catalán, que debemos una vez más a Francesc Eiximenis. En este caso es un antiguo rey de Rávena, de origen campesino, el que enferma, y no sana de todos sus males hasta que vuelve a las gachas y las legumbres con las que se había criado ${ }^{62}$.

¿Hasta qué punto estas historias habían calado en la población? ¿Compartían tales ideas realmente los médicos bajomedievales? Debemos en primer lugar conocer y comprender la escala jerárquica de los alimentos en aquella época, para después comprobar en qué medida se correspondía con la alimentación de las distintas clases sociales, y constatar por último si cuando se prescribía la dieta de un enfermo se tenían o no en cuenta estas supuestas diferencias fisiológicas en función del origen social.

Partiendo de nuevo de las ideas de Galeno y de sus cuatro elementos, la filosofía natural de la Edad Media establecía lo que se ha dado en llamar la "gran cadena del ser", enunciada entre otros por Ristoro d'Arezzo a finales del siglo XIII, y estudiada especialmente por Allen J. Grieco ${ }^{63}$. Según ésta, Dios habría creado de forma similar el mundo natural y el sistema social, siendo ambos dos esquemas verticales y jerárquicos. Este orden hacía que el conjunto de la creación estuviera dividido en cuatro segmentos que representaban a los cuatro elementos -fuego, aire, agua y tierra- con los que, como hemos visto, se relacionaban todas las plantas y los animales. La tierra, siendo el más grosero de los cuatro, estaba en la base, y de ella surgían las plantas, los más humildes de los alimentos. Pero ni tan siquiera todas las plantas eran iguales, porque los bulbos subterráneos, como la cebolla o el ajo, se consideraban las más burdas, siendo un poco mejores aquellas de las que se comían las hojas, como las lechugas o las espinacas, mientras que las frutas, más alejadas del suelo, eran los vegetales de mayor valor, y por tanto los más adecuados para

\footnotetext{
${ }^{61}$ A.J. Grieco, Alimentación y clases sociales, p. 623.

${ }^{62}$ F. Eiximenis, Terç del Crestià, cap. CCXVI, p. 213, citado en J.V. García Marsilla, Alimentación y diferencias sociales, p. 487.

${ }^{63}$ A.J. Grieco, Alimentación y clases sociales, pp.618-621. En la misma centuria Ramon Llull ofrece también en sus obras una clara jerarquía de los alimentos, aunque nunca tan estructurada. En el Arbre de Sciència, por ejemplo, escribe "les gallines e les perdius e-ls peix grosses, qui són pus cares viandes que la carn del bou, el salmó que la sardina"; mientras que en el Llibre de contemplació en Déu detalla que "Així com lo cap de pex qui és pus saborós que la coa, e la lonsa del moltó qui és pus sàbea que la cuixa, e la ala de la gallina qui és pus saborosa que la cuxa" (S. Trias, La cuina lul-liana, p. 855).
} 
los nobles, no contándose desde luego entre ellas las fresas o los melones, criados a ras de tierra. El segundo segmento de esta cadena, asociado al agua, era el pescado, que también se organizaba en función de su cercanía al lecho marino, estando por ello en principio poco valorados los moluscos y crustáceos, mientras que los que tenían tendencia a nadar por la superficie, como delfines y ballenas -que hoy sabemos que lo necesitan porque son mamíferoseran los más apreciados. Después vendría el elemento aire, con las aves organizadas también en función de la altura de su vuelo, y por tanto con los patos y las ocas por debajo, los pollos y capones algo por encima y los pájaros en lo alto, aunque en la cúspide se situaban las águilas y los halcones, hasta el punto de no ser comida habitual por considerarse más bien animales de compañía. Los animales cuadrúpedos, entre la tierra y el aire, no se integraban bien en este esquema, pero en todo caso quedaban por encima de los vegetales y el pescado, y sólo por debajo de las aves. Y sobre todos, como parte del elemento fuego, cercano al sol, estaban animales mitológicos como el fénix.

A partir de ese diseño vertical se suponía que los componentes de aquella sociedad debían tener interiorizada la jerarquía de los alimentos y saber cuáles eran más apropiados para cada clase social. En el Tirant lo Blanc, por ejemplo, un filósofo que se hospedaba en un hostal en espera de ser recibido por la infanta de Sicilia había puesto allí a rustir en el fuego común un trozo de carne de carnero y fue apartado rudamente de la lumbre por un rufià con un conejo que le argumentó: Vós bé veu que jo tinc conill, qui és de major estima, e deu preceir al moltó, així com la perdiu preceïx al conill, per què li deu ésser feta honor ${ }^{64}$. ¡Toda una lección de sabiduría galénica en boca de un proxeneta! Claro que su lectura de esa teoría era aquí interesada y poco tenía que ver con la "calidad" del comensal. Pero si de la literatura vamos ahora a la vida real encontramos casos como el de Lapo Mazzei, el notario y confidente del famoso mercader toscano Francesco di Marco Datini, que le escribe a su amigo diciéndole que no le envíe más perdices porque no es digno de ellas y las va a malgastar, dado que ya no es miembro del consejo de Florencia y no es su deber comer aves. Años antes Lapo incluso le había contado que le gustaban los "alimentos toscos", los que le daban fuerza para trabajar, y le había sugerido que le enviara un tonel de anchoas saladas ${ }^{65}$.

Todo el mundo debía de estar, pues, al corriente de la valoración de cada alimento, y su precio contribuiría sin duda a recordarlo, aunque había manjares, como las citadas perdices, un tanto ambivalentes, muy apreciadas y

\footnotetext{
${ }^{64}$ J. Martorell, M.J. de Galba, Tirant lo Blanc, vol. I, p. 201. Sobre la alimentación en el Tirant véase L. Tudela, Sistemes d'alimentació i usos de taula, y E. Baile, Repertori d'aliments en el Tirant.

${ }^{65}$ A.J. Grieco, Alimentación y clases sociales, pp. 614-615.
} 
al mismo tiempo miradas con recelo por médicos y moralistas. Acabamos de comprobar su alta consideración, al ser ave, aunque de vuelo corto, y además producto frecuente de la caza, el entretenimiento por excelencia de la nobleza. Violant d'Arenós, la esposa del duque de Gandia Alfons el Vell, se permitía por ejemplo el antojo un día de 1371 de que le cocinaran una perdiz para almorzar, y ocho años más tarde, en septiembre de 1379, nada más llegar a Ayora, en el interior valenciano, compraron para ella 26 de estos animales ${ }^{66}$. En realidad no era un capricho demasiado caro, al menos en la Valencia medieval, ya que las ordenanzas sobre los precios de la caza que dictaba el consell municipal en la primera mitad del siglo XIV establecían que no se pagara por una perdiz más de entre 5 y 8 dineros según el año ${ }^{67}$. Eso suponía alrededor de la sexta parte del jornal de un maestro artesano, que podría por tanto permitirse comprar una de cuando en cuando, pero sólo como un lujo, ya que estaría pagando por piezas de menos de $200 \mathrm{~g}$ de carne lo mismo que por más de un kilo de buey o unos $700 \mathrm{~g}$ de carnero ${ }^{68}$.

Pero el prestigio de la perdiz no se traducía sólo en términos económicos, sino que había en ello también importantes componentes simbólicos. Sería por ejemplo relativamente frecuente hasta fechas bien tardías, y en sociedades ya completamente urbanizadas y mercantilizadas, que el rey exigiera como entrada en el establecimiento enfitéutico de alguno de sus monopolios un par de perdices, como ocurre por ejemplo cuando en 1417 un tal Garcia $l o$ Montanyés recibe el guardianatge del carbó de la ciudad de Valencia, un derecho sobre el control de la importación de este producto ${ }^{69}$. Entre los médicos sin embargo las opiniones estaban divididas: mientras Maino de Manieri las consideraba entre las más beneficiosas, por ser las más próximas a la complexión humana, Arnau de Vilanova desconfiaba de ellas y de las codornices por su complexión caliente y seca ${ }^{70}$. Las perdices guardaban de hecho en el imaginario medieval también un lado perverso, porque ya en los bestiarios eran consideradas animales lujuriosos, siempre prestas al coito incluso entre las del mismo sexo, de ahí que en la pintura, sobre todo de los maestros fla-

66 "A dinar a madona I perdiu de casa", ARV, MR 9.606. f. 27r, 10 de febrero de 1371; y ARV, MR 12.537.

${ }^{67}$ A. Furió, F. Garcia-Oliver (eds.), Llibre d'establiments i ordenacions. En 1307 se fijaba el precio en 6 dineros (p. 61), en 1310 en 5 (p. 81), en 1319 en 7 (p. 132), los mismos que en 1323 (p. 143) y que se mantendría en años sucesivos, hasta 1338, en que sube a 8 dineros (p. 339), volviendo a bajar a 7 en 1340 (p. 362).

${ }^{68} \mathrm{El}$ precio del buey rondaba los 5 o 6 dineros la libra (de $1.065 \mathrm{~g}$ ) y el del carnero los 10 dineros (J.V. García Marsilla, La Sisa de la carn, p. 90).

${ }^{69}$ APPV, Protocolos de Jaume d'Anglesola, 12.319, 3 de agosto de 1417. "Ítem que lo dit en Garcia lo Muntanyés done per entrada del dit establiment un parell de perdius". Se comprometía además, y esto era lo económicamente significativo, a pagar un censo anual de 500 sueldos.

${ }^{70}$ Regimen sanitatis ad regem aragonum: Introducción, p. 230. 
mencos y sus imitadores, comenzaran a encarnar al diablo o al pecado. Como consecuencia de todo ello san Bernardino de Siena aconsejaba a las viudas que fueran cuidadosas con su consumo y les decía que no podían ya "hacer lo que hacían cuando tenían marido y comían carne de ave"71. La famosa frase "fueron felices y comieron perdices" con la que nuestro folklore suele acabar muchos cuentos de hadas, podría tener pues un cierto doble sentido, entre el lujo señorial y la concupiscencia de la pareja protagonista.

Sin embargo, volviendo al tema de la discriminación alimenticia, los pocos casos que se pueden hallar en esta época se producen en ambientes y momentos muy concretos en los que se deben reunir personas de distinta condición social. Es lo que ocurría, por ejemplo, en los barcos, en cuyo armamento se distinguían los alimentos para la tripulación y aquellos otros reservados para los oficiales gentilhombres que subieran a bordo. Así, en 1406, en una galera armada por el municipio valenciano, se hace referencia a los ajos, el queso y el aceite que se habían comprado para la xurma y al vino griego que se destinaba al capitán, Vidal de Blanes, y a los hòmens de bé qui ab ell en la dita galera muntarien $^{72}$. De hecho, las ordenanzas navales de la Corona de Aragón, recogidas por Antonio de Capmany, diferenciaban también el pan o la galleta blancos que se debían comprar para el capitán y los altos cargos de la tripulación y los negros que consumía el resto ${ }^{73}$. Y del cumplimiento de estas normativas dan fe las cuentas de abastecimiento de una galera armada en la primera mitad del siglo XV que se conservan en el Arxiu del Regne de València, donde se registra la compra de 98 cafiços y 4 barcelles de forment morisch, es decir, del trigo más oscuro y de peor calidad, para hacer el bescuyt o galleta bizcochada para la tripulación ${ }^{74}$.

Igualmente se yuxtaponen dos menús diferentes cuando un hospital es visitado por sus benefactores o por altos cargos del municipio y la clerecía locales, como ocurre cada año en el de Sant Llàtzer de Valencia con motivo de la fiesta del santo patrón. Sólo para esos invitados de honor se compraban confites y vino griego, como ocurrió en $1406^{75}$. Lo mismo se adquirió dos años más tarde, aunque como un alarde de generosidad se compró entonces

${ }^{71}$ A.J. Grieco, Alimentación y clases sociales, p. 615. Véase I. Malaxecheverría (ed.), Bestiario medieval, p. 151. Sobre los símbolos de la pintura flamenca, E. Panofsky, Los primitivos flamencos.

${ }^{72}$ AMV, Manuals de Consells A-23, f. 56v y 66r, 24 de agosto de 1406.

${ }^{73}$ A. de Capmany, Ordenanzas de las Armadas Navales, p. 101.

${ }^{74}$ ARV, MR 12.279, f. 4v.

75 "Primo doní als capellans qui foren a les vespres e feren col·lació en la qual comprí una lliura de confits de çucre qui costà V s; ítem costà mig quarter de vin grech entre la col·lació e la jornada V s" (AMV, Hospital de Sant Llàtzer 353-1, cuaderno 1, f. 24v). 
también pa de rey -pan blanco de la mejor calidad-per a tota la company ${ }^{76}$. Pero desde luego es en las cortes nobiliarias donde las diferencias en la alimentación se hacen más patentes en un espacio reducido. Pedro el Ceremonioso, por ejemplo, se mostraba bastante obsesionado porque sus domésticos denant Nós no mengen, y llegaba a establecer en sus Ordinacions la ración diaria de cada uno: 30 onzas de pan (887 g); un quarter de vino (3'12 l) para cada seis personas, es decir medio litro para cada uno; un carnero para cada dieciocho personas, y la cantidad de otras carnes que pudiera conseguir el escrivà de ració. Las diferencias parecían aquí expresarse básicamente en la cantidad de comida, ya que el monarca exigía que en su plato se pusiera carne para ocho personas, en la de sus hijos, otros príncipes, arzobispos y obispos para seis; y en la de otros prelados y caballeros para cuatro, cantidades que debían duplicarse con motivo de algunas solemnidades ${ }^{77}$. En la práctica es bastante difícil que estas normativas se cumplieran, pero su simple redacción es la prueba palpable del interés del monarca por hacer visible la jerarquía a través de los alimentos, incluso en su entorno más cercano. Unas diferencias que normalmente se notarían mucho más en ciertos detalles sutiles, como se ve en la corte de los duques de Gandia, donde se anotan a veces las viandas que sólo se destinan a la mesa del señor -alguna perdiz, un capón, langostas, vino griego, pan candeal-y las que se dan a la companya o als servidors como las sardinas, el pescado de morralla, las coles o las cebollas ${ }^{78}$.

Ahora bien, esa divergencia habitual en la alimentación de ricos y pobres, ¿se traducía realmente, como quiere la literatura moralizante, en pautas dietéticas distintas cuando se caía enfermo? Por lo que se deduce de las fuentes de archivo, rotundamente no. En realidad, los alimentos que se consideraban recomendables para recuperar la salud eran siempre los mismos; la diferencia era más bien la capacidad económica para conseguir algunos de ellos, sobre todo cuando la enfermedad se prolongaba. Así, se creían buenos en todos los casos algunos purés o caldos que serían el equivalente a nuestra "dieta blanda" actual, como las farines o el ordiat, este último una papilla de cebada hervida que el protagonista del Espill de Jaume Roig añoraba cuando, tísico, mare ni tia/no m'aculliren/ni mai bulliren/ ordi per mi ${ }^{79}$. Desde luego, aún suponiendo que lo hubieran hecho, los humildes personajes que nos presenta Roig no hubiesen podido aderezar habitualmente este puré con azúcar blanco y leche de almendras como recomienda el Llibre de Sent Soví a unos potenciales lectores bastante más adinerados, pero que también concebían el

\footnotetext{
${ }^{76}$ Ibidem, f. 71r.

${ }^{77}$ Ordinacions de la Casa i Cort, pp. 162- 163.

${ }^{78}$ J.V. García Marsilla, La taula del senyor duc.

${ }^{79}$ J. Roig, Llibre de les dones o Spill, p. 34.
} 
ordiat como un preparado para convalecientes ${ }^{80}$. Igualmente, todos estaban de acuerdo en que el pan blanco era más adecuado para los estómagos delicados de los enfermos, aunque los hospitales no podían ofrecérselo con regularidad a todos sus internos. En el d'en Clapers, por ejemplo, a finales del siglo XIV se compraba pan tierno de moflet especialmente para los veyls malalts, mientras que el personal asistencial y los enfermos más fuertes - malalts esforçats- debían conformarse con el pa de mestall, de trigo mezclado con centeno, sorgo o a veces hasta $\operatorname{arroz}^{81}$.

El alimento reconstituyente y hasta casi medicinal era, no obstante, la carne de ave, y especialmente los pollos y las gallinas, que en ocasiones se llegaban a convertir en el componente casi único de la dieta de algunos enfermos. Desde el rey hasta un humilde artesano, a todos les era recomendado por los médicos el consumo de las carnes blancas de la volateria como parte de su tratamiento. Incluso existía una cierta tolerancia hacia las aves en los períodos de abstinencia, que se puede comprobar prácticamente en toda Europa ${ }^{82}$. A pesar de ello Alfons el Vell, ya anciano, pero temeroso de condenarse, pagaba puntualmente a su confesor todos los días de la cuaresma, como compensación por haber comido un capón o una gallina, mientras el resto de su corte se contentaba con pescado ${ }^{83}$. En su corte, donde muy raro era el día en el que no se consumieran aves, hay numerosas referencias a su carácter de alimento para enfermos. Violant d'Arenós, por ejemplo, comió durante dos días de 1371, estando en Benavarre, una gallina y una perdiz perquè no era sana y el alcaide del castillo de esta localidad, Ramon Pasqual, cuando cayó enfermo de la peste en 1375 se alimentó únicamente de gallinas jóvenes -polles-, caldo de gallina y huevos, con escaso éxito, eso sí, porque murió a los pocos días ${ }^{84}$. También la reina María de Luna, otro personaje de complexión enfermiza, consumía mucha volatería. Día a día se compraban en su corte gallinas en cantidades importantes; por ejemplo, el 26 de abril de 1403, estando en Valencia, su comprador adquirió quince, de las que II parells a brous, es decir, para caldos, que ella bebía con frecuencia, formando parte del instrumental de su cocina una prensa para moler los huesos y hacer con ellos dichos caldos ${ }^{85}$.

${ }^{80}$ Así en la receta del ordiat se dice que se le ponga sal "ha hom que no age febre", y en la de las farines se dice que es para "hom levat de malaltia e que tenpren règeu lo ventrell" (Llibre de Sent Soví, pp. 79-81).

${ }^{81}$ A. Rubio Vela, Pobreza, enfermedad y asistencia hospitalaria, p.144.

${ }^{82}$ Lo detecta en la corte de los duques de Saboya I. Naso, La cultura del cibo, p. 135, y en la de los reyes de Navarra, F. Serrano Larráyoz, La mesa del rey, p. 239.

${ }^{83}$ J.V. García Marsilla, La taula del senyor duc, pp. 57-58.

${ }^{84}$ ARV, MR 9.606, f. 7v-8r y MR 9.620.

${ }^{85}$ ACA, Reial Patrimoni, serie E 24, f. 61r; la cita de la prensa en A. Javierre Mur, María de Luna, p. 119. 
Las casas nobles, de hecho, aunque recurrían al pollo o al caldo de gallina cuando alguno de sus miembros enfermaba, no debían esperar a ello para consumir aves casi a diario. Los citados duques de Gandia incluso organizaban el abastecimiento de gallinas para su corte en poblaciones de la montaña alicantina, como Callosa, Finestrat, Castell de Castells o Guadalest, desde donde llegaban centenares de aves vivas para los corrales del palacio, algunas compradas y otras recibidas como tributo de los vasallos mudéjares de estos lugares ${ }^{86}$. Era éste un lujo que desde luego no todo el mundo se podía permitir. En los hospitales, donde evidentemente se tenían muy en cuenta las supuestas propiedades terapéuticas de las aves de corral, se hacía lo posible por criarlas allí mismo, para así poder suministrárselas cuando fuera necesario a los internos más graves. El Hospital d'en Clapers, por ejemplo, tenía corral propio e intentaba autoabastecerse, aunque raramente lo conseguía del todo, puesto que aún así, lo invertido en gallinas solía triplicar el gasto en medicamentos ${ }^{87}$. Era frecuente incluso dar gallina a algún enfermo concreto y por una razón determinada: por ejemplo, el 6 de enero de 1427, el hospitalero compró una gallina para dos enfermos qui havien presa purga ${ }^{88}$. También en el Hospital de la Reina había un corral, para el que se compraron polles miganceres a obs de criar en 1410, y más tarde partidas de segó (centeno) y dacça (sorgo) con las que las alimentaban ${ }^{89}$. En ambos establecimientos, y en el de Sant Llàtzer, la única especie avícola diferente al pollo que se consumía era la oca, y únicamente un día al año, el de san Juan de junio, en lo que parece que era una tradición festiva muy arraigada ${ }^{90}$. Seguramente por su escasa presencia en el mercado eran más caras, rondando los tres sueldos la unidad, lo mismo que las gallinas más grandes, aunque los ejemplares normales de estas últimas se podían conseguir por entre sueldo y medio y dos sueldos la pieza, lo mismo que los pollos.

Era un precio caro para las economías domésticas de artesanos o pequeños comerciantes, pese a lo cual ante una enfermedad se hacía lo po-

\footnotetext{
${ }^{86}$ J.V. García Marsilla, La taula del senyor duc, pp. 52-54.

${ }^{87}$ En la anualidad 1374-1375 las compras de gallinas alcanzaron los 363 sueldos y 10 dineros, por sólo 139 sueldos y una mealla las medicinas (A. Rubio Vela, Pobreza, enfermedad y asistencia hospitalaria, p. 149).

${ }^{88}$ AMV, Hospital d'en Clapers 350-2, cuadernillo 3, f. 42r.

${ }^{89}$ AMV, Hospital de la Reina 346-1, cuadernillos 2 f. 10r, y 3, f. 54r.

90 “Ítem comprí a XXI de juny per dar refrescament als pobres hun parell e mig d'oques per a la festa de Sent Johan, costaren VIIII s III d", AMV, Hospital de la Reina 346-1, cuadernillo 2, 1410, f. 10r; "Un parell de oques per al dia de Sent Johan, per obs de menjar aquelles en lo dit hospital per los servicials", ibidem, cuadernillo 1, 1406, f. 51r. "Un parell de oques per als servicials e per alcuns dels malalts de aquells en la dita festa, segons és acostumat - V s VI d", AMV, Hospital d'en Clapers 350-2, cuadernillo 1, 1423, f. 42r.; "Ítem costaren I parell d'oques per als malalts per a la festa de Sent Johan - VI sous", AMV, Hospital de Sant Llàtzer 353-1, f 43v. También los frailes de Santa Anna en Barcelona compraban ocas por el día de san Juan (T. Vinyoles, El rebost, la taula i la cuina).
} 
sible por ofrecer a un familiar estos alimentos reconstituyentes. En Sueca, en 1426, entre los gastos de la tutela de un niño huérfano, Pere Reguart, su tutor, el notario Francesc Benet, anotaba: doní un real al dit pubil perque's compràs un parell de polls, que no era sà - I s VI $d^{91}$. Carmen García Herrero documenta también en Zaragoza varias mujeres que salen a comprar pollos para sus maridos dolientes, mientras que una de ellas, la turolense Catalina Muñoz, se queja de que estando ella en cama su marido nunca fue para comprarme una gallina ${ }^{92}$. De hecho se solía también adquirir alguna de estas aves para alimentar a las mujeres que acababan de dar a luz, como se encargan de detallar algunos retablos en los que se representa el nacimiento de la Virgen o de san Juan Bautista, donde sus respectivas madres son alimentadas con gallinas $-\mathrm{o}$ bien con caldos y huevos-, mientras otras mujeres se encargan de los recién nacidos ${ }^{93}$. El problema se presentaba en todo caso cuando la enfermedad se prolongaba -y con ella las compras de estos alimentos caros para hacerle frente-, lo que desequilibraba, a veces sin remedio, el modesto "presupuesto cotidiano" de las familias humildes. Esto es precisamente lo que decía haber padecido un cuchillero de Valencia, Domingo Vinyoles, en 1396, en una reclamación ante el justícia criminal de la ciudad. Contaba que había sido agredido por un musulmán que le dio una cuchillada en una mano, al que le reclamaba no sólo lo que podía haber ganado en el mucho tiempo que estuvo sin poder trabajar, sino además los gastos en médico y cirujano y

en dieta de viandes que ha haüt a haver, viandes a ell no acostumades, com és [sos] dits galines e sos dits polls, que li costen e costaren, més que no aguera fet ab ses viandes comunes, $\mathrm{V}$ florins, poch més o menys ${ }^{94}$.

El testimonio, por más que se trate de un litigio en el que es probable que el declarante cargue las tintas sobre los daños económicos padecidos, es muy revelador tanto del alto coste de esta "dieta de emergencia" como de la voluntad, incluso de los sectores más humildes de aquella sociedad, de seguir las pautas dictadas por sus médicos.

\footnotetext{
${ }^{91}$ E. Guinot, A. Furió, Un exemple d'economia domèstica, p. 45.

${ }^{92}$ M.C. García Herrero, Pan, vino y companage, p. 559.

${ }^{93} \mathrm{P}$. Beseran, El nodriment d'Elisabet i Anna, parteres. La presencia de los huevos podría tener un carácter simbólico, relacionado con la recuperación de la fertilidad, pero también con la pronta recuperación de la mujer (I. González Hernando, Una lectura médica, p. 106). Los villancicos de la época subrayan en cambio como rasgo de pobreza de la Virgen que recién parida "No menjà gallines ni brou destilat" (Cançons nadalenques del segle XV, p. 62).

${ }^{94}$ Es decir, 55 sueldos, ARV, Justícia Criminal 42, 9 de junio de 1396, citado por C. Ferragud, Medicina i promoció social, p. 567.
} 
Seguramente entre los medicamentos que debió pagar Vinyoles había también muchos confeccionados a base de azúcar, puesto que éste hacía furor en estos siglos finales de la Edad Media como base de muchos preparados que se vendían en las boticas, y más en Valencia, donde desde principios del siglo XV su cultivo se expandió por algunas comarcas, exportándose a todas las grandes cortes europeas ${ }^{95}$. Los antidotarios de la época ofrecían muchas recetas de jarabes de azúcar y el De materia medica de Dioscórides, auténtico libro de cabecera de los boticarios medievales, atribuía al azúcar disuelto en agua propiedades curativas contra enfermedades del vientre, el estómago, la vejiga y los riñones ${ }^{96}$. Uno de aquellos boticarios, Francesc Ferrando, tenía, a su muerte en 1475, su "farmacia" llena, y entre todas las medicinas las más abundantes eran los exarobs de sucre, de los que se contaban dieciséis, valorados en conjunto por 78 sueldos y 6 dineros, mientras que su colega Ramon Amalric poseía bastantes años antes, en 1404, una importante cantidad de azúcar almacenada en la despensa de su obrador, casi ciento cincuenta libras, que habrían de servir como materia prima para la confección de estas sustancias curativas ${ }^{97}$.

Por eso a los pasteles y confites, además de su carácter de golosinas, se los consideraba también medicamentos y los vendían los mismos boticarios. Otro de ellos, Arnau Bertran, disponía en 1423 en su obrador de la calle del Malcuinat de Valencia de una premsa de fust per a obrar confits, una taça gran ab sa coha per a obrar confits $i$ dues postetes d'estendre torrons, además de media arroba-unos seis litros-de codonyat (dulce de membrillo) ${ }^{98}$. En forma de jarabes o de confites, la utilización del azúcar como sustancia terapéutica se ve corroborada tanto en las cuentas de los personajes de las clases más elevadas como en las de los hospitales. En la corte de María de Luna en 1403 se compró azúcar en más de cien ocasiones, aunque sólo en seis se especifica que era çucre a malalts ${ }^{99}$. Alfons el Vell, por su parte, compraba este producto en 1411 por panes recién sacados del trapig, que seguramente comenzaban a producirse en la misma comarca de la Safor, y que en las cuentas aparecía

\footnotetext{
${ }^{95}$ Entre las diversas publicaciones que se han hecho sobre el tema destaquemos por ejemplo J. Gisbert (ed.), Sucre \& Borja, y el monográfico de la revista "Afers" 32 (1999), dirigido por F. Garcia-Oliver y titulado Sucre i creixement econòmic a la baixa Edat Mitjana. En concreto sobre su consumo véase J.V. García Marsilla, El luxe dels llèpols.

${ }^{96}$ Dioscórides, Plantas y remedios medicinales, vol. I, lib. II, p. 286.

${ }^{97}$ Respectivamente en ARV, Protocols de Joan de Campos junior 442, 29 de agosto de 1475 , y APPV, Protocols de Guerau de Pont 25.027, 14 de enero de 1404.

${ }^{98}$ ARV, Protocols de Vicent Çaera 2.422, 21 de enero de 1422. La complejidad de los obradores de los boticarios se comprende perfectamente en C. Vela i Aulesa, L'obrador d'un apotecari medieval.

${ }^{99} \mathrm{ACA}$, Reial Patrimoni, sèrie E, 24.
} 
con frecuencia como çucre de casa ${ }^{100}$. Las monjas del monasterio de la Saïdia, la mayoría provenientes de familias acomodadas, compraron también en 1488 azúcar o confites en 35 jornadas, mientras que las de la Puritat eran ya famosas en 1439 por los dulces y jarabes que elaboraban, como el poncirat, la melrosada o la ayguanafa de $\operatorname{ros}^{101}$. En el Hospital de la Reina, en 1410, el administrador Pere de Montsant anotaba también en un listado de los medicamentos que había comprado ese año una libra de azúcar blanco por 2 sueldos y 3 dineros y media arroba de azúcar candí por otros 5 sueldos $^{102}$.

Los beneficios del azúcar en la alimentación se trataban de aprovechar también en la confección de salsas y platos, más incluso en los recetarios catalanes que en los de otros países ${ }^{103}$. Su función era suavizar la fuerza de las especias, y ya Arnau de Vilanova lo prefería a la miel para dulcificar salsas que podían resultar agrias, como la oruga ${ }^{104}$. Lo cierto es que cada vez más platos incluyeron el azúcar como ingrediente: de 41 en el Llibre de Sent Soví a principios del siglo XIV, lo que no llegaba a ser ni el 17\% del conjunto, a 154 de un total de 229 recetas -más del $67 \%$ del total- en el Llibre del coc, de finales del siglo $\mathrm{XV}^{105}$. Aunque esto se debió sobre todo a un cambio en el gusto de las elites, la búsqueda de los sabores agridulces era también, de alguna manera, la del equilibrio humoral; y lo mismo ocurría con el azúcar y las especias que se añadían al vino para formar complejas bebidas espirituosas. El mismo Arnau de Vilanova proporcionaba una receta de piment que, pese a su nombre, no incluía pimienta, sino canela, jengibre blanco, rosas rojas, clavo, sándalo rojo, pelos de espicanardo y miel o azúcar ${ }^{106}$. En cambio, la clarea que elaboraban los monjes de Poblet en 1460 o que compraban ya hecha los de Sant Vicent de la Roqueta de Valencia, sí que contenía pimienta de dos variedades (normal y larga) y miel en lugar de azúcar, junto a canela, jengibre, clavo, lavanda, granos del paraíso y nuez moscada ${ }^{107}$. Se trataba pues de bebidas reconfortantes pero costosas de elaborar y que incluían numerosos ingredientes de un precio elevado, lo que las alejaría del alcance de la mayoría de la población. En lugar de ello, más a mano estaría para muchos el uso de aguardientes, que debían

${ }^{100}$ J.V. García Marsilla, La taula del senyor duc, pp. 122-123.

${ }^{101}$ Respectivamente en ARV, Clero 1.726 y 946. Sobre el monasterio de la Saïdia y sus gastos véase P. Viciano, La gestió econòmica d'un monestir.

${ }^{102}$ AMV, Hospital de la Reina, 346-1, cuadernillo 2, hoja suelta.

${ }^{103}$ En los libros franceses, por ejemplo, el azúcar penetra muy tardíamente, a finales del siglo XIV, y nunca perdió su carácter medicinal (B. Laurioux, La cocina medieval, p. 598).

${ }^{104}$ Arnau de Vilanova. Volum II, p. 179.

${ }^{105}$ B. Santich, L'influence italienne, p. 135.

${ }^{106}$ Arnau de Vilanova. Volum II, p. 187.

${ }^{107}$ A. Altisent, Notes sobre postres, vins i fruita. Sobre estos licores y sus usos médicos véase M.E. González de Fauve, P. de Forteza, "Del beber con moderación". 
estar bastante extendidos si atendemos a la frecuencia con la que aparecen en las casas particulares los alambiques, y que los judíos valencianos compraban con finalidad médica a sus vecinos cristianos, lo que fue taxativamente condenado por el rabino valenciano refugiado en Argelia Isaac ben Seset Perfet, que clamaba contra aquella aigua que diuen aiguardent $i$ que fan els experts gentils per usos medicinals de certes essències i mescles de vi impur ${ }^{108}$.

Arnau de Vilanova, Taddeo Alderotti y otros médicos ya escribieron sobre las propiedades beneficiosas de estos licores destilados, a los que en cierta manera se relacionaba con la alquimia, y Ramon Llull los llegaba a considerar a medio camino entre lo terrenal y lo espiritual. Los dolores de cabeza, la falta de apetito, el dolor de ciática, la gota o los cálculos en la vejiga eran algunas de las dolencias contra las que se recomendaba el uso del aguardiente, a veces cocido con hierbas como salvia, orégano o cilantro ${ }^{109}$. Y es indudable que esas ideas habían calado en la sociedad y llegado incluso a una cierta "cultura popular" que iba mucho más allá de la medicina universitaria, incluyendo a sanadoras y curanderas, o simplemente a las esposas que atendían a sus maridos e improvisaban remedios a partir de las indicaciones médicas ${ }^{110}$.

\section{CAER EN LA TENTACIÓN}

Sin embargo, se empleaban también procesos curativos que se situaban claramente fuera de la medicina culta y que por ello eran más o menos perseguidos ${ }^{111}$, de la misma manera que existían, incluso entre los potentados, prácticas alimenticias que se hallaban en abierta contradicción con lo que los médicos aconsejaban, pese a lo cual esos consumidores no podían evitar "caer en la tentación" de incumplir esos preceptos, ante las delicias gustativas que les proporcionaban. Algunos de estos placeres prohibidos se convirtieron en auténticos signos de distinción en la cúspide de la sociedad, como algunos pescados que alcanzaron renombre a escala continental, a pesar de todos los reparos que los galenos mostraban hacia ellos. El caso más conocido es sin duda el de la lamprea y de otras especies similares a gigantescas anguilas sin escamas en la piel, como el congrio. En general la medicina las miraba con mucho recelo, especialmente a la lamprea, por su supuesta naturaleza fría y

\footnotetext{
${ }^{108}$ R. Magdalena, Aspectes de la vida dels jueus valencians, pp. 195-196. Los alambiques costaban, con hornillo incluido, entre 3 y 5 sueldos en la Valencia medieval. Véase J.V. García Marsilla, La vida de las cosas, p. 25.

${ }^{109}$ R. Cierbide, El aguardiente y el vino.

${ }^{110}$ C. Ferragud, La atención médica doméstica.

${ }^{111}$ R. Narbona, Tras los rastros de la cultura popular.
} 
húmeda, de manera que incluso en Inglaterra se contaba la historia de que el rey Enrique I murió en 1135 después de comer lampreas desafiando los consejos de su médico ${ }^{112}$. Sin embargo, historias como ésta no desanimaron a la aristocracia europea, que continuó considerando a este pescado como el más distinguido, en una actitud desafiante que en todo caso no se acerca ni de lejos al "riesgo lúdico" que se mantiene hoy en ciertos restaurantes japoneses con el pez globo. No hubo de hecho recetario europeo que se preciara que no contuviera algún plato basado en la lamprea; en el caso del Llibre de Sent Soví en forma de empanadas, para las que el animal podía prepararse asado o hervido previamente con vino blanco, aceite, especias, perejil, menta y otras hierbas, antes de enrollarlo en una empanada de harina con especias, cebolla, agraz y azúcar ${ }^{113}$. En otros libros de cocina había por ejemplo una salsa exclusiva para ella, como en el Du fait de cuisine de Chiquart, con su sauce lamproie ${ }^{114}$. La casa real catalano-aragonesa era también especialmente aficionada a ellas, por ejemplo la infanta Mata d'Armagnac, esposa del futuro Juan I, para la que era unos de los pescados más estimados, hasta el punto de que, en 1377, enviaba cartas a la esposa del batle de Tortosa o hasta al mismo obispo de esta localidad, ya que era la zona del Delta del Ebro donde se solían hallar las lampreas, para que le mandaran las primeras que se encontraran, con la exigencia además de que llegaran vivas, para ser el manjar principal en su mesa el día de Jueves Santo ${ }^{115}$. Sin embargo, también las clases burguesas debieron tener acceso a estos pescados -y apreciarlos- cuando el Mesnagier de Paris da recomendaciones a su joven esposa sobre cómo sangrar las lampreas y cómo hacer una salsa con dicha sangre añadiéndole vino y agua ${ }^{116}, \mathrm{o}$ cuando los mercaderes Datini instalados en Pisa disponían de unas especias específicamente da lampreda, es decir, apropiadas para la elaboración de este pescado de agua dulce ${ }^{117}$.

Sin llegar ni mucho menos al nivel de la lamprea, también se observa una cierta contradicción entre el aprecio médico de los mariscos y su presencia, a veces hasta estelar, en las mesas señoriales. Como hemos visto, la "cadena del ser" las situaba muy abajo entre los productos del mar y Arnau

${ }^{112}$ P. Freedman, Lo que vino de Oriente, p. 68.

${ }^{113}$ Llibre de Sent Soví, p. 87.

${ }^{114}$ Receta núm. 27, citada por I. Naso, La cultura del cibo, p. 197.

115 J. Trenchs, El peix a la taula, pp. 315-317. Recordemos en todo caso también el origen francés de esta infanta.

${ }^{116}$ Le Mesnagier de Paris, pp. 693-697. Hay que recordar que en los pocos lugares donde este pez sigue siendo popular hoy en día se siguen haciendo preparados similares con su sangre, como en Arbo (Pontevedra), donde aún se celebra todos los años una Festa da Lamprea entre abril y mayo, o en Burdeos, donde sigue muy viva la receta de la lamproie à la bordelaise.

${ }^{117}$ M. Giagnacovo, Due "alimentazione” del basso Medioevo, p. 825. 
de Vilanova ni los menciona, aunque el llamado "regimen sanitatis" de los Cuatro Maestros llega a recomendar los langostinos entre los frutos del Mediterráneo $^{118}$. Tampoco el precio del langostino era especialmente alto en las tasaciones que hizo la ciudad de Valencia en 1324, pues costaba a 3 dineros la libra como muchos otros pescados ${ }^{119}$. Sin embargo para Alfons el Vell y sobre todo para su hijo, Alfons el Jove, aquella era una de las mayores delicias que podía probar durante la Cuaresma -e incluso fuera de ella- junto con las langostas, de manera que no era difícil encontrar en sus cuentas compras de II dotzenes e miga de langostins per al senyor, a unos precios muy por encima de los regulados, que llegaban a un dinero la pieza y hasta a 22 dineros la langosta ${ }^{120}$. Otros nobles europeos eran igualmente devotos del marisco y los crustáceos, pese a su teórica escasa consideración, como Jean d'Angoulême, que en un semestre de 1462 comió cuarenta especies distintas de peces, crustáceos y mariscos diferentes ${ }^{121}$.

Bastante más sospechosos eran la leche y en general los productos lácteos, posibles portadores de corrupción y enfermedades en estas épocas anteriores a la pasteurización. Los recetarios durante mucho tiempo hicieron más uso de la leche de almendras que de la animal, y Arnau de Vilanova recomendaba "guardarse de la leche", excepto de mediados de abril a finales de mayo, único momento en que según él era profitosa la leche de las cabras, mientras que del queso se podía hacer un uso moderado al final de las comidas ${ }^{122}$. No obstante, en zonas de fuerte tradición ganadera, como Navarra, las compras de leche de vaca y cabra y de quesos frescos eran frecuentes incluso en las cortes reales ${ }^{123}$, mientras que en Aragón ya en el siglo XIII el queso servía como condimento de platos muy diversos pero mayoritariamente sencillos, como las berzas y otras verduras ${ }^{124}$. Al final de la Edad Media, sin embargo, el queso, mucho más que la leche, fue ganando posiciones en el ranking culinario de los alimentos. Esto se debió sobre todo a la mejora en calidad de algunos quesos concretos, que fueron adquiriendo fama, primero franceses como el brie o el roquefort y más tarde también algunos italianos o, a un nivel más modesto,

${ }^{118}$ Regimen sanitatis ad regem aragonum: Introducción, p. 698.

${ }^{119}$ A. Furió, F. Garcia-Oliver (eds.), Llibre d'establiments i ordenacions, p. 148.

${ }^{120}$ J.V. García Marsilla, La taula del senyor duc, p. 65. Si tenemos en cuenta que en una libra de langostinos podían entrar entre 20 y 25 según el tamaño, eso supone un precio por libra siete $\mathrm{u}$ ocho veces superior a lo regulado en Valencia en 1324.

${ }^{121} \mathrm{~F}$. Maillard, Les dépenses de l'Hôtel du comte.

${ }^{122}$ Arnau de Vilanova. Volum II, pp. 172-174.

${ }^{123}$ F. Serrano Larráyoz, Medicina y enfermedad, pp. 157-158.

${ }^{124}$ E. Piedrafita, La alimentación en Aragón, especialmente pp. 111 y 119. 
hispanos, como los quesos de Mallorca, Aragón, Castilla o Sant Mateu ${ }^{125}$. El espaldarazo definitivo a las bondades del queso vendría sobre todo de la mano del tratado De summa laticinorum del italiano Pantaleone da Confienza, llevado a la imprenta en Turín en 1477 en homenaje al duque Luís de Saboya, gran amante de los quesos, que examinaba las principales variedades de Europa y llevaba a cabo una auténtica operación "promocional" de los quesos saboyanos intentando desmantelar la dudosa fama que los lácteos habían tenido hasta entonces. Pocas veces, pues, la teoría médica medieval se puso más claramente al servicio del, por así decirlo, marketing de un producto ${ }^{126}$.

No obstante, si hemos de buscar un tipo de alimentos en el que las discordancias entre las prescripciones médicas y el aprecio de los consumidores medievales son mayores, ése es sin duda la fruta. Ya Pedro el Ceremonioso entona de alguna manera un mea culpa en sus Ordinacions de Cort cuando reconoce que Jacsia que menjar fruytes no sia per meges molt approbat, elles, però, per gràcia dels hòmens són perduÿtes a tast humanal y a continuación le dedica todo un capítulo a las dichas frutas, estableciendo que se le debe dar para su consumo personal -siempre que se pueda- dos piezas antes del almuerzo y una antes de la cena, y a veces también al final si no había neules $a b$ piment o queso en su lugar ${ }^{127}$. Nada -ni sus médicos- podía por tanto frenar la afición del monarca por unos alimentos que eran de los pocos dulces que se podían encontrar entonces de forma natural y que por tanto eran considerados auténticas golosinas. Ni tan siquiera cuando, unos años más tarde -se supone que el núcleo fundamental de las Ordinacions se redactó hacia 1344irrumpió la peste en Europa y los galenos recrudecieron sus amonestaciones contra las frutas, esto se tradujo en una menor afición de todos los sectores de la sociedad por ellas. En efecto, aún con todas las prevenciones, Arnau de Vilanova -que consideraba que las moras causaban epidemias y que decía que no era bueno mezclar varios tipos de frutas porque el estómago no podría asimilar al mismo tiempo sus naturalezas distintas- veía aún ciertas ventajas en

${ }^{125}$ María de Luna compraba con frecuencia quesos de Mallorca, a 6 dineros la libra, y de Aragón, a 6'5; mientras que los Datini de Valencia consumían además de queso mallorquín, también quesos de Castilla, aragonés y de Sant Mateu (J.V. García Marsilla, La jerarquía de la mesa, pp. 203 y 243). El marido de María de Luna, Martín el Humano, pidió ese mismo año que el procurador real de Mallorca, Mateu de Loscos, le enviara "tres-centes peces de formatges redons de Mallorques en tres cosses de palma cascuna ab I senyal reyal" (D. Girona Llagostera, Itinerari del rey en Martí, p. 524). Sobre el queso de Mallorca, véase T. Vinyoles, Notas sobre el queso de Mallorca.

${ }^{126}$ I. Naso, Formaggi del Medioevo; véase para la Corona de Aragón A. Riera Melis, Ganadería, quesos y derivados de la leche.

127 Ordinacions de la Casa i Cort, p. 170. Contradicciones como ésta entre el desprestigio médico y la alta estima gastronómica de las frutas son subrayadas por J. Cruz Cruz, Dietética medieval, pp. 235-255. 
comerlas en verano, porque su humedad y su frío podían temprar la sanch ${ }^{128}$. En cambio Lluís Alcanyís llegaba a incluir en su tratado una historia sobre el padre de Galeno, que nunca enfermó porque jamás comió fruta fresca, y que cuando, una vez muerto su padre, él la probó por primera vez, contrajo febres podrides e de altres febres ${ }^{129}$. Aún así, por mucho que Alcanyís prevenía de la fácil corruptibilidad de las frutas en tiempos de peste, atendiendo a la gran diversidad de fruta que había en Valencia y a la costumbre de comerla, nunca llegó a prohibir su consumo, sino sólo a aconsejar que no se comiesen frutas que llegaran de zonas contaminadas por la epidemia ${ }^{130}$. Por el contrario, existen también tratados de vida y costumbres, en este caso castellanos y algo más tardíos, del siglo XVI sobre todo, como el de Alonso Enríquez de Guzmán, que recomiendan la fruta -e incluso el melón- para curar las fiebres cuartanas ${ }^{131}$.

La abundancia y variedad de frutas que había en todo caso en el País Valenciano eran vistas por Francesc Eiximenis como una de sus grandes riquezas, como una auténtica bendición divina que hacía a esta tierra superior al valle de Hebrón y a la misma Tierra Prometida, que no abunda així en tanta fruita estranya ne en arbres fragants e preciosos com aquesta ${ }^{132}$. De hecho seguramente la imagen de las huertas valencianas medievales ocupadas mayoritariamente por viñas y cereales debería ser al menos matizada si se tienen en cuenta otras fuentes archivísticas hasta ahora no demasiado utilizadas, como por ejemplo los clams o reclamaciones ante los justícies locales, muchas de las cuales tienen que ver con robos de fruta o daños causados a los árboles que la producían. En efecto, junto con las infracciones causadas por el ganado, las relacionadas con los frutales son las más numerosas en cualquier año de los libros del justícia de CCC sous de Valencia. En el de 1438, por ejemplo, encontramos numerosísimas denuncias en este sentido, algunas de las cuales nos hablan especialmente de la importancia y los cuidados que se prodigaban a estos árboles. Así el sastre Pasqual Fontova protestaba contra los mismos oficiales municipales, los guardians de l'orta, porque li han furtats XXVI arbres, dels quals ni havia XIIII empeltats, on havia albercoquers de Domàs, preseguers e alberxichs, e prunes de frare. La precisión en las variedades de frutas descritas y el hecho mismo de que esos árboles estuvieran

${ }^{128}$ Arnau de Vilanova. Volum II, pp. 226-228.

129 J. Gunzberg, La alimentación en los tratados, p. 862.

${ }^{130}$ J.V. García Marsilla, La jerarquía de la mesa, pp. 90-91.

${ }^{131}$ T. de Castro, La alimentación en las crónicas castellanas, pp. 234-235.

${ }^{132}$ F. Eiximenis, Regiment de la cosa pública, pp. 24-25. Eiximenis enumera entre las frutas propias del país "panses blanques e negres, figues, molt oli, ametles, préssecs. pomes, peres, teronges, llimons, llimes, adzebrons, aranges, cireres de diverses sorts, guíndoles, albercocs, magranes, gínjols, nous, avellanes, sarmenyes, lledons, garrofes, prunes, nesples, codonys, albèrxiques, ab molts d'altres". 
injertados -empeltats- denotan un interés y un grado de conocimiento de la fruticultura realmente alto ${ }^{133}$. Seguramente los frutales formaban parte en la mayoría de los casos de los lindes naturales entre las parcelas de que solían disponer los campesinos valencianos, como la tancha de tarongers e pomeres que estaba colocada en torno al huerto de Miquel Munyoç, mestre d'esgrima, y que había sido talada por el ganado del carnicero Mateu Fabregat, según Munyoç se quejaba en el mismo año $1438^{134}$. Sin embargo en algunos casos es ya posible la existencia de lo que entonces se conocía como camps espesos, plantados todos ellos de frutales, como podría ser el que Pere Ossinyà, cura de Massamagrell, poseía a su muerte en 1411, descrito como un ort e camp on ha molts terongers, que és VII fanechades, contigu a la casa del senyor del dit loch de Carraxet, en la que es la referencia más antigua a un huerto valenciano de naranjos de la que disponemos hasta ahora ${ }^{135}$.

Se habrá notado, en todo caso, que ninguno de los propietarios de frutales que hemos citado hasta ahora era propiamente labrador, sino que se trataba de propietarios urbanos, en su mayoría artesanos o comerciantes, que dedicaban sus pequeños huertos a conseguir las muy preciadas frutas. Lo mismo se observa con frecuencia en las muchas alquerías que algunos personajes más adinerados de la ciudad, como mercaderes o abogados, poseían y solían arrendar a mitges a campesinos, reservándose en exclusiva para ellos la cosecha de manzanas, peras, higos o cerezas que dieran los árboles de la propiedad ${ }^{136}$. También los hospitales disponían de cuidados huertos, cuya producción a veces hasta daba para vender en el mercado local. Así en el de la Reina se registran en 1416 III dotzenes de poncirs que.s colliren en l'ort de l'espital e foren venuts - VII $s^{137}$. Aunque sin duda el que más datos nos proporciona sobre los trabajos en los huertos y su producción es el Hospital de Sant Llàtzer o leprosería, propietario de limoneros y poncirers en el camí de Morvedre y de numerosas viñas, además de rosales cuyas flores servían para las aguas medicinales que allí se preparaban. En enero de 1407 compraron además seis árboles para plantar, en què havia dos preseguerets empeltats e IIII magraners

${ }^{133}$ ARV, Justícia de 300 sous 1.082, s.f., sábado 11 de enero de 1438. También en las huertas del Xúquer abundan estos clams relacionados con los frutales, como demostrara A. Furió, El camperolat valencià.

${ }^{134}$ Ibidem, f. 1r, 2 de enero de 1438.

135 ACV, Protocols de Lluís Ferrer 3.675, 20 de enero de 1411. Habría que aclarar en todo caso que éstas serían naranjas amargas, anteriores a la llegada de las dulces que trajeron los portugueses de la China a finales del siglo XV. Sobre la difusión de los cítricos con la mediación de los musulmanes, véase A. Riera Melis, Las plantas que llegaron de Levante, especialmente pp. $832-835$.

${ }^{136}$ J.M. Cruselles, Producción y autoconsumo, especialmente pp. 70-71.

${ }^{137}$ AMV, Hospital de la Reina, 346-1 vol. 3, f. 16v. 
dolços, mientras que en diciembre del mismo año a estos árboles se unieron otros IIII magraners dolços, una prunera de frare e I albericoquer ${ }^{138}$. Compraban de hecho los plantones en el mismo mercado de la ciudad, como nos informa el hospitalero Joan Armenguer unos años más tarde, en 1435, cuando anota:

Item comprí en lo mercat II pomeres, dos presegués de Sent Johan, dos berxiqués e un magraner dolç e II nespleres, los quals arbres plantí en los orts della casa per ço com eren molt despoblats d'arbres, costaren posats en casa - XI s VIIII ${ }^{139}$.

La producción frutera, por tanto, debía alcanzar un cierto volumen en las huertas valencianas, y su fama era conocida por los monarcas, que a menudo reclamaban que les enviaran algunas piezas para su consumo personal. Ya Ramon Muntaner da cuenta del envío de naranjas valencianas a Zaragoza en 1286 para los juegos acuáticos que se iban a desarrollar sobre el Ebro en honor al rey Alfonso el Liberal ${ }^{140}$. Mucho más tarde, en la década de 1440, Juan II, siendo aún infante y rey de Navarra, solicitaba a Orihuela desde Alicante que le enviara los mejores melones, duraznos y alberchicos y figos que las podades haver $^{141}$. E incluso es muy probable la implicación de los mismos monarcas en la importación de frutales desconocidos hasta el momento en el país, que comenzarían a cultivarse en sus huertos del Real de Valencia o del Palau Reial Major de Barcelona, como los azarollers (acerolos) que reclamaba Martín el Humano a Pere Bertran, quien los tenía que traer desde Sicilia en $1403^{142}$.

Sin embargo, la mayor parte del consumo de frutas sería, dado su carácter perecedero, de ámbito local, y los listados de especies distintas que aparecen por ejemplo en la mesa de los duques de Gandia son tan amplios que contradicen abiertamente la máxima de Arnau de Vilanova de que no se debían comer juntas diferentes frutas. Incluso, lo mismo que los reyes, no dudaban en hacer que sus vasallos las transportaran de uno a otro de sus señoríos: como las manzanas que, estando Alfons el Jove en Gandia en 1415, se hacía traer desde Cortes de Arenoso, a más de $200 \mathrm{~km}$ de distancia, lo que le costaba, sólo en los gastos del mensajero, 22 sueldos $^{143}$. Sin embargo, lo

\footnotetext{
${ }^{138}$ AMV, Hospital de Sant Llàtzer 353-1, primer cuaderno, ff. 23v y 69v. Costaron los seis primeros árboles 5 sueldos, y los segundos otro tanto.

${ }^{139}$ Ibidem, $2^{\circ}$ cuadernillo, f. 29 r.

${ }^{140}$ R. Muntaner, Crònica, p. 810, citado por A. Riera Melis, Las plantas que llegaron de Levante, pp. 833-834.

${ }^{141}$ J. Hinojosa, Textos para la historia de Alicante, pp. 180-181.

${ }^{142}$ D. Girona Llagostera, Itinerari del rey en Martí, p. 523.

${ }^{143}$ J.V. García Marsilla, La taula del senyor duc, p. 95.
} 
que más corroía la conciencia de su padre Alfons el Vell era comer cerezas en Cuaresma. Le debía parecer un placer tan pecaminoso que pagaba por ello a su confesor lo mismo que cuando comía carne en día de abstinencia ${ }^{144}$. De hecho las cerezas eran un verdadero símbolo de la llegada de la primavera, diminutas exquisiteces con las que celebraban el buen tiempo hasta los enfermos mentales del Hospital d'Innocents, que las tomaban por el día del Corpus en $1413^{145}$. Estos frutos rojos encerraban además un cierto mensaje afectivo o hasta erótico, ya que era un regalo habitual entre enamorados y en la pintura gótica no faltan los banquetes, especialmente el de Herodes, con el baile de Salomé incluido, en que las cerezas no aparezcan diseminadas por la mesa como símbolo de lujuria ${ }^{146}$.

Las frutas seguían por tanto situándose en un plano ambivalente, entre el pecado y la enfermedad por un lado, y el goce y la salud por otro, por lo que los médicos buscaron medios para convertirlas en un alimento más saludable y algunas fueron ganando reconocimiento por su capacidad para enfrentarse a algunas dolencias concretas. A las ciruelas, por ejemplo, Arnau de Vilanova les reconocía su capacidad para mol-lificar lo ventre, es decir, para combatir el estreñimiento y, con el fin de hacerlas más suaves, en el Hospital de la Reina las escaldaban antes de dárselas a los enfermos ${ }^{147}$. Por el contrario, las que Vilanova llamaba fruites pòntiques, qui an natura de costrèyer (estreñir), se encontraban especialmente indicadas en situaciones como los asedios, de manera que en un memorial que Alfonso el Magnánimo envió a todos los castillos del reino de Valencia durante la guerra con Castilla de 1429-30, indicándoles los pertrechos de los que debían disponer, incluía, además de haver metge de cirorgia con todos sus ungüentos, tener almacenado codonyat (dulce de membrillo) que restreny aquells qui hajen mal de corrença per estar a la serena o per beure aigua o vinagre ${ }^{148}$.

Hasta los poco apreciados melones fueron paulatinamente siendo valorados para algunos casos, especialmente para bajar el calor de la sangre o la agudeza de la cólera, cosa que Arnau de Vilanova aconsejaba que se hiciera

${ }^{144}$ Ibidem, p. 97.

${ }^{145} \mathrm{ADV}$, Llibres de l'Hospital dels Innocents V I/b, junio de 1413.

${ }^{146}$ Como en la escena representada en el retablo de los Santos Juanes del castillo de Santa Coloma de Queralt, obra de Joan de Tarragona de finales del siglo XIV, conservado en el Museu Nacional d'Art de Catalunya, cat. 156.

${ }^{147}$ AMV, Hospital de la Reina 346-1 vol. 2, f. 10r: "Comprí lo dia mateix miga rova de prunes escaldades obs dels malalts". Los consejos de Vilanova en Arnau de Vilanova. Volum II, p. 145 .

${ }^{148}$ ARV, Reial Cancelleria 643, ff. 370r-371r. Agradezco a Jorge Sáiz la noticia sobre este documento. 
bastante antes de la cena ${ }^{149}$. Con todo, el melón seguía teniendo la reputación de ser la fruta más peligrosa, de manera que se fueron introduciendo formas de comerlo que contrarrestaran su excesiva humedad. Así comenzó en Italia en el siglo XV la costumbre de tomarlo con jamón, algo que parece tan actual y que se basa ni más ni menos que en los principios del equilibrio galénico; en Francia en el siglo XVI se comenzó a comer sazonado con sal y pimienta y bebiendo vino ${ }^{150}$, e incluso en España viejos refranes aconsejan que "después del melón, vino al montón" o "al pepino, vino, y al melón con más razón". También las peras con vino, azúcar y canela comenzaron a imponerse en esta época y en general fue una práctica creciente el confitado de las frutas, una costumbre tras la que, además de algunas influencias islámicas, se hallaba también el deseo médico de moderar la naturaleza agresivamente húmeda de las frutas carnosas con el siempre medicinal azúcar o con miel. De ahí que el Llibre de totes maneres de confits, el primer tratado de confitería en catalán, que también es de mediados del siglo XV, esté compuesto en su mayor parte por recetas de mermeladas, jaleas y frutas hervidas con azúcar, canela o miel ${ }^{151}$.

Por tanto, y para concluir, el recorrido que hemos realizado confrontando la tradición médica y la culinaria con los documentos generados por las prácticas cotidianas del consumo, nos ha llevado a comprobar la complejidad de las relaciones entre las tres esferas y ha demostrado que no basta comparar los regimina médicos con los recetarios de gastronomía para comprender la evolución de la dieta de los europeos de hace quinientos o seiscientos años. Ambos corpus no eran, al fin y al cabo, sino construcciones teóricas, por más que, evidentemente, tuvieran un cierto influjo sobre las costumbres reales de quienes tenían acceso a ellas de una u otra forma. Su función era sobre todo ofrecer unas pautas sobre el régimen de vida a seguir, pero en muchas ocasiones da la impresión de que las teorías no iban ni mucho menos por delante de los hábitos de la población, sino que, al contrario, tendían a autorizar, o incluso a ensalzar, los comportamientos de unas clases dominantes que a menudo se veían incapaces de controlar. Por otro lado, se ha podido comprobar también la diferencia palpable entre la ficción generada por los moralistas, que trataban de sancionar el orden social establecido concibiendo normas de salud diferentes para ricos y pobres, y la realidad, que sólo conocía una valoración de la salubridad de los alimentos, ampliamente extendida, pero a la que se tenía un mayor o menor acceso en función de las posibilidades económicas de cada uno. Los

\footnotetext{
${ }^{149}$ Arnau de Vilanova. Volum II, p. 149.

${ }^{150}$ J.L. Flandrin, Condimentación, cocina y dietética, pp. 637-639.

${ }^{151}$ Llibre de Sent Soví, pp. 242-295.
} 
tratados médicos o culinarios son pues, por supuesto, excelentes fuentes históricas para el estudio de la historia de la alimentación, pero nos proporcionan únicamente un marco, a veces incluso bastante parcial, en el que encuadrar los comportamientos cotidianos de la población. Es necesario ir más allá, atender a otras fuentes y a otras variables que expliquen los cambios y las persistencias en las formas de consumo que han ido diseñando nuestros hábitos actuales. Al fin y al cabo, esa máxima tan vigente hoy en día de "somos lo que comemos" parece extraída de alguna forma de los tratados médicos medievales, pero sigue sin bastarnos para saber por qué comemos lo que comemos.

\section{BIBLIOGRAFÍA CITADA}

Agramunt, Jaume d', Regiment de preservació de la pestilència, Barcelona, Enciclopèdia Catalana, 1998.

Alcanyís, Lluís, Regiment preservatiu e curatiu de la pestilència, ed. de A. Ferrando e intr. de J.M. López Piñero, Valencia, Ajuntament de València, 1999.

Altisent, Agustí, Notes sobre postres, vins i fruita, al segle XV, "Boletín de la Sociedad Castellonense de Cultura" 46/2 (1970), pp. 236-242.

Arnau de Vilanova. Volum II: obres mèdiques, ed. de M. Batllori, Barcelona, Barcino, 1947.

Aurell, Jaume; Puigarnau, Alfons, La cultura del mercader en la Barcelona del siglo XV, Barcelona, Omega, 2001.

Baile, Eduard, Repertori d'aliments en el Tirant. E dinaren-se ab molt gran plaer, en "Tirant" 12 (2009), pp. 5-31.

Banegas, Ramon Agustí, Europa carnivora. Comprar y comer carne en el mundo urbano bajomedieval, Gijón, Trea, 2012.

Barrio, Juan Antonio, Finanzas municipales y mercado urbano en Orihuela durante el reinado de Alfonso V (1416-1458), Alicante, Ayuntamiento de Orihuela - Institut Juan Gil-Albert, 1998.

Bernard de Gordon, De conservatione vitae humanae, a die nativitatis usque ad ultimam horam mortis, Bratislava, 1570.

Bertran, Prim, El menjador de l'Almoina de la Catedral de Lleida. Notes sorbe l'alimentació dels pobres lleidatans, "Ilerda" 40 (1979), pp. 89-124.

Beseran, Pere, El nodriment d'Elisabet i Anna, parteres. Observacions sobre un aspecte iconogràfic dels Naixements de la Verge i el Baptista al Gòtic, en Ier Col-loqui d'Història de l'Alimentació a la Corona d'Aragó, Edat Mitjana, vol. II, Lleida, Institut d'Estudis Ilerdencs, 1995, pp. 871-884.

Birlouez, Eric, À la table des seigneurs, des moines et des paysans du Moyen Âge, Rennes, Ouest-France, 2009. 
Cançons nadalenques del segle XV, ed. de J. Romeu, Barcelona, Barcino, 1949.

Capmany, Antonio de, Ordenanzas de las Armadas Navales de la Corona de Aragón aprobadas por el rey Pedro IV, Madrid, Imprenta Real, 1787.

Castro, Teresa de, La alimentación en las crónicas castellanas bajomedievales, Granada, Universidad de Granada, 1996.

Cervantes, Miguel de, El ingenioso hidalgo don Quijote de la Mancha, ed. de V. Gaos, Madrid, Gredos, 1987.

Cierbide, Ramón, El aguardiente y el vino como componentes de remedios medicinales según los manuscritos medievales, "Revista Internacional de Estudios Vascos" 52/1 (2007), pp. 11-79.

Cifuentes, Lluís, La ciència en català a l'Edat Mitjana i el Renaixement, Barcelona, Universitat de Barcelona - Palma de Mallorca, Universitat de les Illes Balears, 2002.

Cipolla, Carlo, Miasmi e umori: ecologia e condizione sanitaria in Toscana nel Seicento, Bolonia, Il Mulino, 1989.

Cruselles, José María, Producción y autoconsumo en contratos agrarios de la huerta de Valencia (siglos XIV y XV), en Ier Col-loqui d'Història de l'Alimentació a la Corona d'Aragó, Edat Mitjana, vol. II, Lleida, Institut d'Estudis Ilerdencs, 1995, pp. 61-78.

Cruz Cruz, Juan, Dietética medieval. Apéndice con la versión castellana del "Régimen de Salud" de Arnaldo de Vilanova, Huesca, La Val de Onsera, 1997, pp. 235-255.

Dioscórides, Plantas y remedios medicinales (De Materia médica), Madrid, Gredos, 1998.

Echániz, María, La alimentación de los pobres asistidos por la Pía almoina de la catedral de Barcelona según el libro de cuentas de 1283-1284, en Alimentació i societat a la Catalunya medieval, Barcelona, CSIC, 1988, pp. 173-261. (Anuario de Estudios Medievales; 20).

Eiximenis, Francesc, Com usar bé de beure e menjar, selección del Terç del Crestià a cargo de Jorge J.E. Gracia, Barcelona, Curial, 1977.

Eiximenis, Francesc, Regiment de la cosa pública, ed. de Daniel de Molins de Rei, O.M., Barcelona, Barcino, 1927.

Eiximenis, Francesc, Terç del Crestià, ed. de Martí de Barcelona y Norbert d'Ordal, Barcelona, Barcino, 1932.

Ferragud, Carmel, La atención médica doméstica practicada por mujeres en la Valencia bajomedieval, "Dynamis" 27 (2007), pp. 133-155.

Ferragud, Carmel, Medicina i promoció social a la Baixa Edat Mitjana (Corona d'Aragó, 1350-1410), Madrid, CSIC, 2005. 
Flandrin, Jean-Louis, Condimentación, cocina y dietética durante los siglos $X I V, X V$ y XVI, en Flandrin, Jean-Louis; Montanari, Massimo (dirs.), Historia de la Alimentación, Gijón, Trea, 2004 (ed. original en francés en 1996), pp. 623-645.

Flandrin, Jean-Louis, Diététique et gastronomie, XIVe-XVIe siècles, en Jansen-Sieben, Ria; Daelemans, Frank, Voeding en Geneeskunde. Alimentatrion et médicine, Actes du colloque de Bruxelles, Bruselas, Archives et Bibliothèques de Bélgique, 1993, pp. 177192.

Freedman, Paul, Lo que vino de Oriente. Las especias y la imaginación medieval, Valencia, Publicaciones de la Universitat de València, 2010 (original en inglés, 2008).

Furió, Antoni, El camperolat valencià en l'Edat Mitjana: demografia i economia rural en la Ribera (segles XIII-XVI), Valencia, Universitat de València, 1986, (tesis doctoral inédita).

Furió, Antoni; Garcia-Oliver, Ferran (eds.), Llibre d'establiments i ordenacions de la ciutat de València I (1296-1345), Valencia, Publicaciones de la Universitat de València, 2007.

Gallent, Mercedes, La asistencia sanitaria en Valencia (1400-1512), Valencia, Universitat de València, 1980, (tesis doctoral inédita).

García Ballester, Luís, La búsqueda de la salud. Sanadores y enfermos en la España medieval, Barcelona, Península, 2001.

García Herrero, María del Carmen, Pan, vino y companage: apuntes sobre la alimentación en la Baja Edad Media aragonesa, en Ier Col-loqui d'Història de l'Alimentació a la Corona d'Aragó, Edat Mitjana, vol. II, Lleida, Institut d'Estudis Ilerdencs, 1995, pp. 549-563.

García Marsilla, Juan Vicente, La jerarquía de la mesa. Los sistemas alimentarios en la Valencia bajomedieval, Valencia, Centre d'Estudis d'Història Local, 1993.

García Marsilla, Juan Vicente, Puresa i negoci. El paper dels jueus en la producció i comercialització de queviures a la Corona d'Aragó, "Revista d'Història Medieval" 4 (1993), pp. 161-182.

García Marsilla, Juan Vicente, Alimentación y diferencias sociales en la ciudad de Valencia (1390-1415), en Ier Col-loqui d'Història de l'Alimentació a la Corona d'Aragó, Edat Mitjana, vol. II, Lleida, Institut d'Estudis Ilerdencs, 1995, pp. 487-505.

García Marsilla, Juan Vicente, L'alimentazione in ambito mercantile. I conti della Filiale Datini di Valencia (1404-1410), en Cavaciocchi, Simonetta (ed.), Alimentazione e nutrizione (secc. XIII-XVIII). Atti 28 Settimane di Studi dell'Istituto di Storia Economica "F. Datini", Firenze, Le Monnier, 1997, pp. 831-839. 
García Marsilla, Juan Vicente, El luxe dels llèpols. Sucre i costum sumptuari a la València tardomedieval, "Afers" 32 (1999), pp. 83-99.

García Marsilla, Juan Vicente, La Sisa de la Carn. Ganadería, abastecimiento cárnico y fiscalidad en los municipios valencianos bajomedievales, en Vallejo Pousada, Rafael (ed.), Los tributos de la tierra. Fiscalidad y agricultura en España (siglos XII-XX), Valencia, Publicaciones de la Universitat de València, 2008, pp. 81-101.

García Marsilla, Juan Vicente, La vida de las cosas. El mercado de objetos de segunda mano en la Valencia medieval, ponencia al congreso Pautes de consum i nivells de vida al món rural medieval, Valencia 18-20 de septiembre de 2008, accesible en la web: www.uv.es/consum/marsilla.pdf [consulta: 25/04/2013].

García Marsilla, Juan Vicente, Diferencia e integración. Las formas de la vida cotidiana entre los mudéjares y moriscos valencianos, en Benítez Sánchez-Blanco, Rafael; García Marsilla, Juan Vicente (eds.), Entre tierra y fe. Los musulmanes en el reino cristiano de Valencia (12381609), Valencia, Publicaciones de la Universitat de València - Ministerio de Cultura - Bancaixa, 2009, pp. 341-361.

García Marsilla, Juan Vicente, La taula del senyor duc. Alimentació, gastronomia i etiqueta a la cort dels Ducs Reials de Gandia, Gandia, CEIC Alfons el Vell, 2010.

García Marsilla, Juan Vicente; López Gila, M.D.; Rosselló, M., Localització d'unes possibles carnisseries medievals al barri de la Xerea (València), "Qulayra" 2 (2006), pp. 113-138.

García Verdeguer, Carmen, Una meselleria en la Valencia del Quinientos. El Hospital de Sant Llàtzer, Valencia, Universitat de València, 1990, (tesis de licenciatura inédita).

Garcia-Oliver, Ferran (dir.), Sucre i creixement econòmic a la baixa Edat Mitjana, "Afers" 32 (1999).

Giagnacovo, Maria, Mercantia tavola. Prezzi e consumialimentaridell'azzienda Datini di Pisa (1383-1390), Florencia, Opus Libri, 2002.

Gil-Sotres, Pedro, Regimen sanitatis ad regem aragonum: Introducción, en García Ballester, Luis; McVaugh, Michael R. (eds.), Regimen sanitatis ad regem aragonum. Arnaldi de Vilanova Opera Medica Omnia. X.1, Barcelona, Universitat de Barcelona - Fundació Noguera, 1996.

Girona Llagostera, Daniel, Itinerari del rey en Martí (1396-1402), “Anuari de l'Institut d'Estudis Catalans"' (1911-1912), pp. 81-184.

Gisbert, Josep (ed.), Sucre \& Borja. La canyamel dels Ducs: del trapig a la taula, Gandia, CEIC Alfons el Vell, 2000.

González de Fauve, María Estela; De Forteza, Patricia, "Del beber con moderación”. Usos y aplicaciones del vino según los tratados médicos 
de la España Bajomedieval y de la temprana modernidad, "Historia, Instituciones, Documentos" 32 (2005), pp. 175-191.

González Hernando, Irene, Una lectura médica de las imágenes medievales del nacimiento, "Anales de Historia del Arte" volumen extraordinario (2010), pp. 91-109.

Grieco, Allen J., Alimentación y clases sociales a finales de la Edad Media y en el Renacimiento, en Flandrin, Jean-Louis; Montanari, Massimo (dirs.), Historia de la Alimentación, Gijón, Trea, 2004 (ed. original en francés en 1996), pp. 611-624.

Guinot, Enric; Furió, Antoni, Un exemple d'economia domèstica de principis del XVè. L'administració d'una tutela. Sueca 1412-27, "Quaderns de Sueca" 1 (1980), pp. 11-46.

Gunzberg, Jordi, La alimentación en los tratados de preservación y curación de la peste, en Ier Col-loqui d'Història de l'Alimentació a la Corona d'Aragó, Edat Mitjana, vol. II, Lleida, Institut d'Estudis Ilerdencs, 1995, pp. 857-869.

Hinojosa, José, Textos para la historia de Alicante. Historia Medieval, Alicante, Institut Juan Gil-Albert - Diputación de Alicante, 1990.

Jansen-Sieben, Ria, From Food Therapy to Cookery-Book, en Kooper, Erik (ed.) Medieval Dutch literature in European context, Cambridge, Cambridge University Press, (1994), pp. 261-279.

Javierre Mur, Antonio, María de Luna, reina de Aragón, Madrid, CSIC, 1942. Jerez, Felipe, Els còdexs pictòrics del Tacuinum Sanitatis d'Ibn Butlan, "Afers" 41 (2002), pp. 83-98.

Laudan, Rachel, Origen de la dieta moderna, monográfico sobre "La dieta humana: biología y cultura", "Investigación y Ciencia (edición española de Scientific American)", 66, (2011), pp. 37-42.

Laurioux, Bruno, Spices in the Medieval diet; a new approach, "Food and Foodways" 1 (1985), pp. 43-76

Laurioux, Bruno, Le registre de cuisine de Jean de Bockenheim, cuisinier du Pape Martin V, "Mélanges de l'Ecole Française de Rome" 100 (1988), pp. 709-760.

Laurioux, Bruno, L'histoire de la cuisine: problèmes, sources et méthodes. L'exemple du Moyen Âge (XIIIe - XVe siècles), en Cavaciocchi, Simonetta (ed.), Alimentazione e nutrizione secc. XIII-XVIII. Atti delle 27e Settimane di Studi dell'Istituto Internazionale di Storia Economica F. Datini, Firenze, Le Monnier, 1997, pp. 463-487.

Laurioux, Bruno, La cocina medieval (siglos XIV y XV), en Flandrin, Jean-Louis; Montanari, Massimo, Historia de la Alimentación, Gijón, Trea, 2004 (ed. original en francés en 1996), pp. 589-609. 
Laurioux, Bruno, Cuisine et médecine au Moyen Âge: alliées ou enemies?, "Cahiers de Recherches Médiévales" 13 (2006), pp. 223-238.

Le Mesnagier de Paris, ed. de G.E. Brereton y J.M. Ferrier, París, Le Livre de Poche, 2010.

Le Régime du corps de maître Aldebrandin de Sienne, ed. de L. Landouzy y R. Pepin, París, H. Champion, 1911.

Llibre de Sent Soví. Llibre de totes maneres de potatges de menjar, ed. de Rudolf Grewe, revisada por Amadeu-J. Soberanas y Joan Santanach, Llibre de totes maneres de confits, ed. crítica de Joan Santanach i Suñol, Barcelona, Barcino, 2003.

López Piñero, José María, La medicina como norma de la vida humana en el galenismo y las "Tablas de salud" de Ibn Butlan, en Theatrum sanitatis: Biblioteca casanatense, Barcelona, Moleiro, 1999, pp. 11-45.

Magdalena, Ramon, Aspectes de la vida dels jueus valencians a la llum d'unes fonts hebràiques: les respostes de Rabí Yishaq Ben Seset Perfet (segona meitat del segle XIV), "Afers" 7 (1988-1989), pp. 189-206.

Maillard, François, Les dépenses de l'Hôtel du comte Jean d'Angoulême pour le second semestre 1462, en Les problèmes de l'alimentation, "Bulletin philologique et historique du CTHS" (1971), pp. 119127.

Malaxecheverría, Ignacio, (ed.), Bestiario medieval, Madrid, Siruela, 1986.

Martorell, Joanot; Galba, Martí Joan de, Tirant lo Blanc, ed. de Martí de Riquer, Barcelona, Edicions 62 - "La Caixa", 1983.

Montanari, Massimo, L'image du paysan et les codes de comportement alimentaire, en Boglioni, P., et al. (eds.), Le petit peuple dans l'Occident médiéval: Terminologies, perceptions, réalités, París, Publications de la Sorbonne, 2002, pp. 97-112.

Muntaner, Ramon, Crònica, "Les quatre Grans Cròniques” ed. de Ferran Soldevila, Barcelona, Barcino, 1971.

Narbona, Rafael, Tras los rastros de la cultura popular. Hechicería, supersticiones y curanderismo en la Valencia medieval, "Edad Media. Revista de Historia" 1 (1998), pp. 91-110.

Naso, Irma, Formaggi del Medioevo. La "Summa laticinorum” di Panatleona da Confienza, Turín, Il Segnalibro, 1990.

Naso, Irma, La cultura del cibo. Alimentazione, dietetica, cucina nel basso medioevo, Turín, Paravia Scriptorium, 1999.

Nicoud, Marilyn, La dietética medieval: textos y lectores, "Minerva. Revista de Filología Clásica" 23 (2010), pp. 15-34.

Ordinacions de la Casa i Cort de Pere el Cerimoniós, ed. de F.M. Gimeno, D. Gozalbo y J. Trenchs, Valencia, Publicaciones de la Universitat de València, 2009. 
Orlandi, Angela, Mercaderies i diners: la correspondència datiniana entre València i Mallorca (1395-1398), Valencia, Publicaciones de la Universitat de València, 2008.

Panofsky, Erwin, Los primitivos flamencos, Madrid, Cátedra, 1998 (original en inglés de 1953).

Patni, Rashmi, L'assaisonnement dans la cuisine française entre le XIVe et le XVIe siècle, Paris, École des Hautes Études en Sciences Sociales, 1989, (tesis doctoral inédita).

Piedrafita, Elena, La alimentación en Aragón en el siglo XIII: el modelo clerical y el nobiliario, "Revista de Historia Jerónimo Zurita" 80-81 (2005-2006), pp. 99-132.

Riera i Sans, Jaume, La conflictivitat de l'alimentació dels jueus medievals (segles XII-XIV), en Alimentació $i$ societat a la Catalunya medieval, Barcelona, CSIC, 1988, pp. 295-311. (Anuario de Estudios Medievales; 20).

Riera Melis, Antoni, Ganadería, quesos y derivados de la leche en el Medioevo catalano-aragonés, en Atti del convegno internazionale "Il Caseario, un archetipo alimentari: il latte e la sua metamorfosi", Bolonia, Il Mulino, 1983, pp. 47-57.

Riera Melis, Antoni, Las plantas que llegaron de Levante, Acerca del legado alimentario islámico en la Cataluña medieval, "Anuario de Estudios Medievales" 31/2 (2001), pp. 787-841.

Robert, Mestre, Libre del coch, ed. de Veronika Leimgruber, Barcelona, $\mathrm{Cu}$ rial, 1977.

Roig, Jaume, Llibre de les dones o Spill, Barcelona, Barcino, 1928.

Rubio Vela, Agustín, Pobreza, enfermedad y asistencia hospitalaria en la Valencia del siglo XIV, Valencia, Institució Alfons el Magnànim, 1984.

Sanchis Sivera, Josep, Bibliología valenciana medieval, "Anales del Centro de Cultura Valenciana" III (1930), reeditado en Sanchis Sivera, J., Estudis d'Història Cultural, ed. de M. Rodrigo Lizondo, Valencia, Institut Interuniversitari de Filologia Valenciana - Barcelona, Publicacions de l'Abadia de Montserrat, 1999.

Santich, Barbara, L'influence italienne sur l'évolution de la cuisine médiévale catalane, en Manger et boire au Moyen Âge, vol. II, Niza, PFLSHN, 1984, pp. 131-140.

Scully, Terence, Du fait de cuisine par Maistre Chiquart, 1420, "Vallesia" 40 (1985), pp. 101-231.

Scully, Terence, The Opusculum de Saporibus of Magninus Mediolanensis, "Medium Aevum" 54 (1985), pp. 158-207.

Scully, Terence, Mixing it up in Medieval Kitchen, en Medieval Food and Drink, vol. XXI, Binghampton, Center for Medieval and Early Renaissance Studies, 1995, pp. 1-26. 
Scully, Terence, The Art of Cookery in the Middle Ages, Woodbridge, The Boydell Press, 1995.

Sentieri, Maurizio, Un'indagine sulle ragioni della persistenza della dietetica galenica lungo l'età preindustriale, en Cavaciocchi, Simonetta (ed.), Alimentazione e nutrizione secc. XIII-XVIII. Atti delle 27e Settimane di Studi dell'Istituto Internazionale di Storia Economica "F. Datini", Firenze, Le Monnier 1997, pp. 787-795.

Serrano Larráyoz, Fernando, La Mesa del rey. Cocina y régimen alimentario en la corte de Carlos III el Noble de Navarra (1411-1425), Pamplona, Gobierno de Navarra, 2002.

Serrano Larráyoz, Fernando, Medicina y enfermedad en la corte de Carlos III el Noble de Navarra (1387-1425), Pamplona, Gobierno de Navarra, 2004.

Thorndyke, Lynn, A Medieval Sauce-Book, "Speculum" 9 (1934), pp. 183190.

Trenchs, Josep, El peix a la taula de la princesa Mata d'Armanyac: els capritxos $i$ gustos d'una infanta, en Ier Col-loqui d'Història de l'Alimentació a la Corona d'Aragó, Edat Mitjana, vol. II, Lleida, Institut d'Estudis Ilerdencs, 1995, pp. 309-328.

Trias, Sebastià, La cuina lul-liana. Criteris dietètics i nivells socials, en Ier Col-loqui d'Història de l'Alimentació a la Corona d'Aragó, Edat Mitjana, vol. II, Lleida, Institut d'Estudis Ilerdencs, 1995, pp. 845856.

Tudela, Lluís; Castells i Puig, Francesc, Sistemes d'alimentació i usos de taula al "Tirant lo Blanc", en Ier Col-loqui d'Història de l'Alimentació a la Corona d'Aragó, Edat Mitjana, vol. II, Lleida, Institut d'Estudis Ilerdencs, 1995, pp. 693-719.

Vela i Aulesa, Carles, L'obrador d'un apotecari medieval segons el llibre de comptes de Francesc ses Canes (Barcelona, 1378-1381), Barcelona, CSIC, 2003.

Verdés, Pere, Una espècia autòctona. El comerç del safrà a Catalunya durant el segle XV, "Anuario de Estudios Medievales" 31/2 (2001), pp. 757785.

Viciano, Pau, La gestió econòmica d'un monestir cistercenc femení: la Saïdia de València a la fi del segle XV, "Revista d'Història Medieval" 2 (1991), pp. 111-132.

Vinyoles, Teresa, El rebost, la taula i la cuina dels frares barcelonins al 1400, en Alimentació $i$ societat a la Catalunya medieval, Barcelona, CSIC, 1988, pp. 137-166. (Anuario de Estudios Medievales; 20).

Vinyoles, Teresa, Notas sobre el queso de Mallorca, "Bolletí de la Societat Arqueològica Luliana" 47 (1991), pp. 75-88. 
Woolgar, Chris M., Banquetes y ayunos. La comida y el sentido del gusto en la Europa medieval, en Freedman, Paul (ed.), Gastronomía. Historia del paladar, Valencia, Publicaciones de la Universitat de València, 2007, pp. 163-195.

Fecha de recepción del artículo: noviembre 2012

Fecha de aceptación y versión final: abril 2013 